\title{
BIOMARKERS IN THE DIAGNOSIS AND THERAPY OF ALLERGIC DISEASES AND ASTHMA
}

\author{
Heimo Breiteneder ${ }^{1}$, Yaqi Peng ${ }^{2}$, Ioana Agache ${ }^{3}$, Zuzana Diamant ${ }^{4}$, Thomas Eiwegger ${ }^{5}$, \\ Wytske Fokkens $^{6}$, Claudia Traidl-Hoffmann ${ }^{7}$, Kari Nadeau ${ }^{8}$, Robyn O'Hehir ${ }^{9}$, Liam \\ O'Mahony $^{10}$, Oliver Pfaar ${ }^{11}$, Maria Torres ${ }^{12}$, De Yun Wang ${ }^{13}$, Luo Zhang ${ }^{14}$, and Cezmi \\ $\operatorname{Akdis}^{15}$ \\ ${ }^{1}$ Medical University of Vienna \\ ${ }^{2}$ Swiss Institute of Allergy and Asthma Research \\ ${ }^{3}$ Transylvania University of Brasov \\ ${ }^{4}$ Institute for Clinical Science, Skane University Hospital, Lund University \\ ${ }^{5}$ The Hospital for Sick Children \\ ${ }^{6}$ University of Amsterdam \\ ${ }^{7}$ Institute of Environmental Medicine, UNIKA-T \\ ${ }^{8}$ Stanford University \\ ${ }^{9}$ The Alfred Hospital \\ ${ }^{10}$ University College Cork National University of Ireland \\ 11 University Hospital Marburg, Philipps-Universität Marburg, Marburg, Germany. \\ 12 Regional University Hospital of Malaga-IBIMA-UMA-BIONAND-ARADyAL \\ ${ }^{13}$ Yong Loo Lin School of Medicine, National University of Singapore \\ ${ }^{14}$ Beijing TongRen Hospital, Capital Medical University, \\ ${ }^{15}$ University of Zurich
}

July 21, 2020

\begin{abstract}
Modern healthcare requires a proactive and individualized response to diseases, combining precision diagnosis and personalized treatment. Accordingly, the approach to patients with allergic diseases encompasses novel developments in the area of personalized medicine, disease phenotyping and endotyping and the development and application of reliable biomarkers. A detailed clinical history and physical examination followed by the detection of IgE immunoreactivity against specific allergens still represents the state of the art. However, nowadays, further emphasis focuses on the optimization of diagnostic and therapeutic standards and a large number of studies have been investigating the biomarkers of allergic diseases, including asthma, atopic dermatitis, allergic rhinitis, food allergy, urticaria and anaphylaxis. Various biomarkers have been developed by omics technologies, some of which lead to a better classification of the distinct phenotypes or endotypes. The introduction of biologicals to clinical practice increases the need for biomarkers for patient selection, prediction of outcomes and monitoring, to allow for an adequate choice of the duration of these costly and long-lasting therapies. Escalating healthcare costs together with questions on the efficacy of the current management of allergic diseases requires further development of a biomarker-driven approach. Here, we review biomarkers in diagnosis and treatment of asthma, atopic dermatitis, allergic rhinitis, viral infections, chronic rhinosinusitis, food allergy, drug hypersensitivity and allergen-immunotherapy with a special emphasis on specific IgE, microbiome and epithelial barrier. In addition, EAACI guidelines on biologicals are discussed within the perspective of biomarkers.
\end{abstract}




\section{Keywords}

Biomarkers, asthma phenotypes and endotypes, allergic rhinitis, food allergy, allergen immunotherapy, biologicals.

\section{Introduction}

Allergic diseases represent a group of conditions caused by hypersensitivity of the immune system to allergens present in the environment. ${ }^{1}$ These diseases include food allergies, asthma, atopic dermatitis (AD), allergic rhinitis (AR), conjunctivitis, and other co-morbidities and complications, such as chronic rhinosinusitis with or without nasal polyposis (CRSwNP). ${ }^{2-4}$ The 100 year old personalized allergen-specific management of allergic diseases has been a particular advantage in our specialty contributing to the early awareness of personalized approaches and precision medicine. The use of multiple omics, big data, and systems biology have demonstrated a profound complexity and dynamic variability and enabled the discovery of novel biomarkers. ${ }^{5}$

Biomarkers represent measurable indicators linking an underyling pathway to a phenotype or endotype of a disease. ${ }^{6-8}$ Regrettably, current biomarkers are not precise in selecting the specific endotype that will respond to a targeted treatment. A good example is the observation that blood eosinophilia predicts therapeutic response to all currently available or future-targeted interventions in severe asthma (i.e. anti-IL-5, IL-4 /IL-13, anti-IgE-targeted treatment, CRTH2 antagonists). ${ }^{8,9}$ Precision medicine in allergic diseases demands accurate diagnoses ${ }^{10}$, which mostly rely on the combination of the clinical history and respective gold standards, which are all subject to the operator, observer and interpretation variability ${ }^{11,12}$. Some of the approaches are time-consuming, and in vivo challenges may result in severe side effects and, in rare cases, even death. Therefore, the discovery, validation and clinical applicability of molecular biomarkers become increasingly important. ${ }^{13}$

The cellular, biochemical, or molecular changes in allergic patients which are measurable in blood, sputum or nasal secretions can be considered as biomarkers. ${ }^{14}$ These biomarkers are used for disease diagnosis, selection of targeted therapy, disease monitoring and prediction of prognosis. ${ }^{15}$ Except for the well-known biomarkers (e.g, IgE, blood or sputum eosinophilia, fractional exhaled nitric oxide [FeNO] $),{ }^{16-18}$ research focusing on proinflammatory mediators, genes, epithelial barrier and microbiomes are now emerging, which highlight more potential biomarkers for allergic diseases. ${ }^{19,20}$ Some of the biomarkers showing a strong ability in identifying disease endotypes or phenotypes may also act as therapeutic targets. ${ }^{21,22}$ This article reviews the biomarkers identified to date and potential targeted therapy in allergy. In addition, it briefly reviews the biomarkers taking place in EAACI guidelines.

\section{Biomarkers in asthma}

In the past decades, it has been increasingly recognized that asthma is a highly heterogeneous disorder with different underlying mechanisms and pathways translating into variable responses to standard treatment across the different subsets or clinical phenotypes. ${ }^{23,24}$ Unbiased approaches and cluster analyses identified four major clinical phenotypes, i.e .: (1) early-onset allergic asthma, (2) early-onset allergic moderate-tosevere asthma, (3) late-onset non-allergic eosinophilic asthma, and (4) late-onset non-allergic non-eosinophilic asthma. ${ }^{25}$ The late-onset subsets tend to present as more severe or more difficult-to-treat than early onset asthma. To promote an adequate treatment strategy, asthma can be subdivided into Type 2 (high) and nonType 2 (or Type 2 low) endotypes based on their underlying inflammatory pathways. ${ }^{26}$ As part of a more general syndrome often including nasal polyps with or without NSAID-Exacerbated Respiratory Disease (NERD), ${ }^{27,28}$ Type2 asthma currently comprises the best defined asthma subset(s) in terms of underlying immunopathology, corresponding biomarkers ${ }^{8}$ and targeted treatment options with biologicals and small molecules. ${ }^{13,29,30}$

In parallel with the available (targeted) treatment options, biomarkers have been validated along the corresponding inflammatory pathways aimed for pheno/endotyping and to guide treatment for Type 2 asthma. ${ }^{8}$ Clinically applicable point-of-care biomarkers include blood eosinophils, or whenever feasible, sputum eosinophil counts, serum specific IgE and FeNO. ${ }^{8,31}$ Although overlapping in type 2 biomarkers may 
occur within patients, all biomarkers represent different aspects of the type 2 inflammatory pathways with IgE associating to allergy, while FeNO is linked to the IL-13 pathway and epithelium-derived inflammation. ${ }^{8}$ Based on these point-of-care biomarkers in combination with clinical characteristics (age of onset, comorbidities, exacerbations, need for maintenance systemic corticosteroids) and physiological parameters (lung function, airway hyperresponsiveness, etc.), current guidelines have now adapted algorithms which can help to predict a response to (targeted) treatments and/or can be used to monitor the subsequent treatment response. ${ }^{23,32,33}$ In this context, some confounders have been recognized for the existing point-of-care biomarkers, i.e ., for FeNO mainly related to ICS use, smoking, dietary nitrate intake, virus infections and bronchoconstriction, while for blood eosinophils circadian variation, parasites and systemic corticosteroids were found to be the most common perturbing factors. ${ }^{23,34}$ In this context, a clinically relevant issue has been raised, i.e., whether "true" non-Type 2 (non-eosinophilic) asthma really exists among patients with severe asthma, given the fact that high-dose inhaled and oral corticosteroids may potentially mask preexisting Type 2 inflammation interfering with its biomarkers, especially blood eosinophils and FeNO. ${ }^{35,36}$ Currently ongoing corticosteroid-tapering studies (RASP-UK) in patients with non-Type 2 severe asthma should answer this question. Alternatively, airway neutrophilia ("neutrophilic asthma") may often reflect (subclinical) airway infection. ${ }^{36-38}$

In contrast, for non-Type 2 asthma which is by default defined as asthma without type2 biomarkers, underlying pathways and, hence, clinically applicable biomarkers and targeted treatment options are still largely under exploration. ${ }^{36,39}$ Apart from most patients with mild clinically stable asthma, ${ }^{26,40}$ clinical phenotypes frequently associated with non-Type 2 asthma include very late-onset asthma (women), obesity-associated asthma, smoking-associated neutrophilic asthma and pauci-granulocytic asthma. Although generally based on increased sputum neutrophils or absence of normal levels of (sputum) eosinophils and neutrophils (paucigranulocytic) with normal levels of other Type 2 markers, the diagnosis of non-type 2 asthma is difficult to establish as often based on cross-sectional data potentially affected by confounders including respiratory infections or anti-inflammatory therapies. ${ }^{36}$ In the absence of targeted biologicals, in non-Type 2 asthma treatable traits should be targeted, ${ }^{41-43}$ e.g.: obesity, smoking habits, psychological aspects, neutrophilia as a potential indicator of respiratory infection and airway narrowing or airway hyperresponsiveness as an indicator of ASM dysfunction, while corticosteroids may not be effective and should be tapered off (Figure 1). ${ }^{23}$

In conclusion, despite substantial progress in our understanding, applicable biomarkers and targeted treatment options for Type 2 asthma, further characterization of molecular pathways by omics technologies, ${ }^{44-46}$ sophisticated imaging ${ }^{47}$ and innovative anatomical approaches ${ }^{48}$ should help to further unravel the complexity of asthma and to define reliable (composite) biomarkers and therapeutic strategies for patients non-responsive to currently available (targeted) treatment options including non-Type 2 asthma.

\section{Biomarkers linked to Microbiome and Asthma}

An enormous variety of microbes colonize mucosal body surfaces and these microbes are organized within complex community structures, utilizing nutrients from other microbes, host secretions and the diet. Modern lifestyles, medications and social interactions have fundamentally altered and disrupted the human microbiome metacommunity and, as a consequence, risk of immune-mediated diseases such as allergy and asthma. ${ }^{49,50}$ The mechanisms that mediate host-microbe communication are highly sophisticated and are being intensely investigated by many research groups across the world. However, there is accumulating evidence that microbiome composition and metabolic activities within the gut and the airways can influence asthma pathogenesis. ${ }^{51-53}$ Here, we summarize some of the key recent findings that identify specific microbes or associated metabolites that may be useful as biomarkers to predict asthma risk, asthma severity or guide existing or novel therapies.

Alterations in the gut microbiota within the first year of life have been associated with asthma risk in multiple birth cohort studies. ${ }^{19}$ The lower relative abundance of genera including Lachnospira, Veillonella ,Faecalibacterium, Rothia, Bifidobacterium andAkkermansia in the gut during early life have been associated with the development of asthma. ${ }^{54,55}$ While fewer studies have examined pre-school children (2-4 years of age), a 
recent study in this age group demonstrated that certain bacterial genera within the gut were still associated with wheezing (Collinsellaand Dorea) or subsequent development of asthma (Gemmigerand Escherichia ). ${ }^{56}$ In addition to the gut microbiota, studies are also showing changes in the microbial populations of the airways. Microbial diversity and the relative abundances of Veillonella and Prevotella in the airways at age one month were associated with asthma by age 6 years. ${ }^{57}$ Interestingly, higher relative abundance of these bacteria was associated with reduced TNF- $\alpha$ and IL-1 $\beta$ and increased CCL2 and CCL17 within the airways. A switch from aCorynebacterium and Dolosigranulum cluster in the upper-airways to a Moraxella cluster was associated with a higher risk of severe asthma exacerbation in children with asthma. ${ }^{58}$ In adults, increased relative abundance of the phylum Proteobacteria (including Haemophilus, Comamonadaceae, Sphingomonadaceae ,Nitrosomonadaceae, Oxalobacteraceae andPseudomonadaceae) is often associated with asthma or with worse asthma control. ${ }^{59}$ Microbial changes within the gut, upper and lower airways of adult asthma patients are magnified in obese asthma patients and in those with severe disease ${ }^{60}$ Bronchoalveolar lavage levels of IL-5 and eosinophils correlated with a variety of microbes within the airways. Of note, severe asthma negatively correlated with fecal Akkermansia levels and oral administration of Akkermansia to murine models significantly reduced airway hyper-reactivity and airway inflammation (Figure 2).

In addition to microbiota composition, microbial metabolites may also be useful biomarkers in asthma. The fecal metabolome of children at increased risk of asthma contained increased levels of pro-inflammatory metabolites, among which 12, 13 DiHOME was able to induce IL- 4 production in CD4 ${ }^{+} \mathrm{T}$ cells and decreased the abundance of Tregs. ${ }^{55}$ High levels of short chain fatty acids (SCFAs), such as butyrate and propionate, at one year of age were associated with reduced risk of atopic sensitization and asthma by school age. ${ }^{61}$ Multiple immune modulatory effects have been described in murine models for SCFAs, which include the promotion of Treg development and the inhibition of pulmonary ILC2 functions and subsequent development of airway hyper-reactivity. ${ }^{62}$ In adults, an increased abundance of histamine secreting bacteria were observed within the gut of patients with asthma, while disease severity correlated with high levels of the histamine secreting microbeMorganella morganii ${ }^{63}$ Murine models have demonstrated that bacterial-derived histamine within the gut can influence inflammatory responses within the lungs. ${ }^{64}$

In the future, the application of recent advances in metagenomic sequencing technologies and bioinformatics will likely lead to the identification of novel functional traits and metabolites within the gut and airway microbiome of asthma patients. ${ }^{65}$ In addition, future asthma studies should include the microbiome as potential biomarkers that predict or associate with responses to biologics, as already observed for Faecalibacterium ,Bifidobacterium and Akkermansia that associate with immunotherapy responses in certain groups of cancer patients. ${ }^{66}$

\section{Skin bacterial microbiome as clinical biomarker in atopic eczema}

Diagnosis of atopic eczema (AE) severity is still today a semi-quantitative clinical score based on subjective information from the patients together with doctor's subjective estimation on severity of the skin lesions and patient's history of itching and sleep loss. ${ }^{67,68}$ In the era of targeted therapy, and thus more complex therapy management requirements, more objective criteria are urgently needed. A diagnostic biomarker would also have the potential to differentiate between the different subgroups of $\mathrm{AE}$. AE, likewise, lacks a prognostic biomarker: $\mathrm{AE}^{69}$ affects $30 \%$ of children but only $5 \%$ of adults - thus the question remains who keeps the disease, who emerges from it, and who embarks on the full career of an atopic individual. Skin microbiome dysbiosis, measured either as microbiome diversity or more reliably as abundance of $S$. aureus, was shown to correlate with both the AE clinical score and the expression of skin barrier molecules. ${ }^{70}$ It is still a matter of scientific debate whether the relative frequency of various bacteria (e.g., S. aureus frequency as obtained from $16 \mathrm{~S}$ based NGS) is an adequate biomarker or rather the absolute microbial load (e.g., as obtained from qPCR) is better. Furthermore, is it enough to quantify the DNA abundance from non-standardized amounts of skin samples, or rather is the absolute microbial load of standardized skin samples needed?

S. aureus is important for AE pathogenesis even though it is still a matter of debate whether overgrowth of $S$. aureus is a cause or a result of barrier disruption. ${ }^{71}$ Thus, microbiome analysis, at least on the species level, but ideally on the strain level, would enables us to identify personalized biomarkers. This highlights 
a methodological drawback, as currently tools for annotation on species level are not reliable. Furthermore, the current methods for skin microbiome measurement are not standardized; testing the same material in different laboratories is prone to give different results. For skin microbiome to be used clinically as a biomarker, standardized methodology needs to be developed and validated so it can be reliably used across different laboratories. ${ }^{72}$ Combinatory biomarkers between skin microbiome and biomarkers of type 2 immunity would also be of great potential. ${ }^{73}$ Recently, biofilm propensity of S. aureus skin isolates - as a cause and possible target has become more and more of a central issue. ${ }^{74}$ Thus, resolving the enigma of skin-microbe interaction as a function of skin homeostasis has to take more players into the. ${ }^{75}$

In conclusion, skin bacterial microbiome shows great potential to be used as a clinically important biomarker for atopic eczema. To reach this aim, we need to perform prospective clinical trials and large longitudinal registries that include skin microbiome testing. Furthermore, it is critical to advance standardized and foremost quantitative methodologies for skin bacterial microbiome analysis. New technologies, such as single molecule real time, need to be further developed and tested in order to improve skin microbiome analysis with higher accuracy and/or longer sequencing length. Collaboration between large academic consortia and pharmaceutical companies is essential for such endeavors.

\section{Biomarkers in diagnosis of allergic rhinitis}

With deeper insights into mechanisms of AR, novel biomarkers have recently been identified in its diagnosis. Furthermore, several immune cells and mediators, genes and metabolites have been studied to explore their potential utilization in diagnosis of AR.

\section{Immune cells andmediators}

Several potential immune cells (granulocytes, lymphocytes, etc.) and mediators might serve as diagnostic biomarkers of AR. ${ }^{14,76}$ Izuhara and colleagues have reported that induction and increased expression of periostin reflect type 2 inflammation and remodelling, and could be regarded as an emerging biomarker for allergic diseases. ${ }^{77}$ One study has demonstrated that allergen-induced surface CD203c expression on basophils exhibits a time-of-day-dependent variation, and allergen-specific basophil reactivity shows daily variations depending on circadian clock activity in basophils, which could partly be responsible for temporal symptomatic variations in AR. ${ }^{78}$ One recent study has suggested that circulating group 2 innate lymphoid cells (ILC2s) may play an important role in the pathology of AR, particularly as increased levels of ILC2scorrelated with symptom scores and IL-13 levels in house dust mite (HDM)-sensitized AR patients, ${ }^{79}$ and these cells produce large amounts of proinflammatory mediators in response to Th2 cytokines. ${ }^{80,81}$ Indeed, a more recent study by Tojima and colleagues found that prostaglandin D2 (PGD2) and cysteinyl leukotriene (cysLTs) might induce ILC2s to produce Th2 cytokines such as IL-5 and IL-13 ${ }^{82}$ Similarly, ST2-expressing pathogenic memory T helper (Th) 2 cells, producing substantial amounts of IL-33-induced IL-5 and IL-13, have been shown to be linked to sensitization and the onset and progression of AR (Figure 3). ${ }^{83}$

\section{Genes}

Epigenetic modifications, particularly DNA methylation and microRNAs (miRNAs), might have the potential to identify AR patients. One recent study has demonstrated changes in DNA methylation in tryptase gamma 1 (TPSG1), schlafen (SLFN12), and mucin 4 (MUC 4 ), following controlled allergen challenge, and suggested that baseline epigenetic status may act as a potential biomarker for AR symptom severity. ${ }^{84}$ An-

other recent study has indicated that nasal epigenome associated with asthma, FeNO and IgE may serve as a sensitive biomarker of asthma, allergy and airway inflammation in children. ${ }^{85}$ Other studies have reported that subsets of circulating miRNAs are solely expressed in the blood of patients with AR and asthmatics and may therefore be used as non-invasive biomarkers for diagnosis and characterization of these diseases. ${ }^{86,87}$

\section{Metabolites}

Metabolites have also been proposed as biomarkers for AR. A very recent study of serum metabolomics has demonstrated that at least nine metabolites (13(S)-HPODE, bilirubin, leukotriene D4, hypoxanthine, Lstercobilinogen, N-succinyl-L-diaminopimelic acid, chlorophyll b, 15-hydroxyeicosatetraenoic acid, and urate) 
were significantly altered in the serum of AR patients, and therefore may provide a better understanding of the metabolic pathways involved in the aetiology of AR. ${ }^{88}$ Additionally, decreased serum lactoferrin level has been reported to be associated with the phenotype ofDermatophagoides pteronyssinus (Der p1 )-sensitive $\mathrm{AR}$, and in combination with serum Der 1 -specific IgE level, may serve as a serologic biomarker for early detection of AR. ${ }^{89}$

\section{Biomarkers in therapy of allergic rhinitis}

Currently, optional therapeutic measures for AR involve patient education, environmental control, pharmacotherapy, allergen immunotherapy (AIT), and surgery. ${ }^{90,91}$ Traditional medications include nasal corticosteroids, antihistamines, mast cell stabilizers, decongestants, etc. MP29-02, a combination of nasal corticosteroid and antihistamine, is a novel topical medication which has proved to be effective in reducing nasal hyperreactivity and nasal mediators such as substance $\mathrm{P}$, in patients with AR. ${ }^{92}$ As ILC2s have been shown to produce significant amounts of proinflammatory mediators in response to epithelium-derived cytokines $^{80,81}$ and PGD2 and cysLTs ${ }^{82}$ in AR patients, agents targeting the ILC2s and the mediators activating these cells have become targets for therapy. Rittchen and Heinemann have recently reviewed the central role of hematopoietic PGD2 synthase in allergic inflammation and indicated that PGD2 signaling might be a promising therapeutic target for AR, as PGD2 can activate Th2 cells, eosinophils and basophils. ${ }^{93}$ Indeed, a randomized controlled phase II clinical trial has recently demonstrated that ONO-4053, a novel prostaglandin D receptor 1 antagonist, was more effective than pranlukast, a leukotriene receptor antagonist, in treating patients with seasonal AR. ${ }^{94}$ Most recently, emerging studies have focused on biologics for treating allergic diseases; especially severe, uncontrolled asthma and $\mathrm{AD}$, as well as AR. ${ }^{95,96}$ To date a high number of specific biologics targeting markers of Th1/2/17 inflammation have been introduced; with more under development. ${ }^{95,97}$ In particular, targeting IgE by omalizumab, a recombinant humanized anti-IgE antibody, has been shown to significantly improve symptoms in patients with inadequately controlled AR. ${ }^{98}$ Furthermore, combining omalizumab with sub-cutaneous immune therapy (SCIT) in patients with SAR and comorbid seasonal allergic asthma has been shown to lead to greater clinical improvements in AR and lung function than SCIT alone. ${ }^{99}$ Similarly, dupilumab, a biologic which targets IL-4R $\alpha$ to block the activity of both IL-4 and IL-13, has been shown to provide nasal symptom relief in patients with uncontrolled asthma and comorbid AR. ${ }^{100}$

\section{Biomarkers of viral infections in exacerbation of allergic rhinitis and asthma}

Text box: Respiratory viral infections may exacerbate chronic airway inflammatory diseases, including allergic inflammation through both Type 2 (e.g., IL-25, IL-33 and TSLP) and non-type 2 (e.g., IFN types I and III, RIP3, OSM, MCIDAS) mechanisms.

Over the past decade, our understanding of immunological mechanisms underlying allergic diseases such as AR has substantially increased through the discovery of $\mathrm{T}$ helper $(\mathrm{Th})$ subsets and their importance in allergic inflammation. Emerging data now provide new insights on the type 2 immune response that is an immune response to allergens and involves Th2 cells, type $2 \mathrm{~B}$ cells, ILC2s, type 2 macrophages, a small fraction of IL-4-secreting NK cells, IL-4-secreting NK-T cells, basophils, eosinophils and mast cells. ${ }^{101}$ At the same time, it has also been established that viral infection synergizes with allergic inflammation causing more severe exacerbations and symptoms compared to both conditions alone. ${ }^{102,103}$ There is increasing evidences that most respiratory viral infections could trigger or exacerbate chronic type 2 inflammatory responses via excessive release of chemokines and cytokines into the airways. ${ }^{104-106}$ While much of these studies focuses on lower airway inflammatory diseases instead of AR; insights from these studies can be applied to ongoing studies of viral induced AR exacerbations and the search for its associated markers.

Like other chronic airway inflammatory diseases, AR patients also suffer from altered responses and potentially increased susceptibility towards viral infection. ${ }^{107-109}$ This is similarly due to the reduced type III interferon response, which is crucial against incoming viral infection in the upper airway. ${ }^{107-109}$ Hence, markers for virus induced AR exacerbation may have significant overlap with findings from other inflammatory airway diseases. Proinflammatory cytokines such as TNF- $\alpha$, IL-4, IL-5, IL-13, RANTES, Eotaxin, TSLP, 
IL-25 and IL-33 are usually expressed at higher concentrations in chronically inflamed airways, some of which are also found in AR. ${ }^{101,110,111}$ These cytokines can be further triggered directly or indirectly by viral induced IFNs, cytokines and chemokines. Infections such as RSV can even further shunt antiviral responses towards a more type 2 centric response. ${ }^{112-116}$ In addition, the discovery of ILC2s, a group of lymphoid cells, further emphasized the role of epithelial alarmins IL-25, IL-33 and TSLP in viral induced exacerbation. ${ }^{117}$ During viral infection, these three cytokines were secreted in response to epithelial injury. ${ }^{118-120}$ They then activate ILC2s to further secrete type 2 cytokines IL-4, IL-5 and IL-13, aggravating type 2 inflammation in the airway, resulting in acute viral exacerbation. Interestingly, these factors are not released readily and do not activate ILC2s in virus-infected healthy individuals, but effectively augment type 2 responses in chronically inflamed airways (Figure 4).$^{121,122}$

In addition, respiratory viral infections may also exacerbate chronic airway inflammatory diseases, including allergic inflammation through other non-type 2 mechanisms, in which other markers can also be used as an indicator of these exacerbations. Viral infections can lead to the destruction of epithelial barrier and disruption of mucociliary function due in part to cell death in the virus infected epithelium. Hence, markers for cell death (e.g. RIP3) and mucociliary dysfunction (e.g. MCIDAS) constitute part of the viral exacerbation repertoire. ${ }^{112}$ Viral infection also causes increase in factors such as OSM and ANGPTL4 which disrupts tight junctions leading to increased allergen invasion and their contact with immune cells in the sub-epithelium region, thereby exacerbating allergic symptoms. ${ }^{123,124}$ In addition, miRNAs are increasingly implicated in the mis-regulation of inflammatory responses and several of them are found to be dysregulated in an inflamed airway. For example, expressional changes of miRNAs such as miR-21 may coincide with viral infection responses and hence linked to viral induced exacerbations. ${ }^{125}$ Finally, an emerging field of bioenergetics and mitochondrial function may also contribute to the mechanism of viral induced exacerbation in AR. Oxidative stress and mitochondrial dysfunction from viral infection may induce increased inflammation and thus ROS and its associated markers may potentially serve as key markers for viral exacerbation. ${ }^{126,127}$

\section{Biomarkers in chronic rhinosinusitis}

CRS, like asthma, can be divided into different pheno- and endotypes. The mostly used phenotype is the division into CRS with and without nasal polyps (CRSwNP and CRSsNP), although many other pheno- and endotypes are known. ${ }^{28,128}$ However, recently, the options to treat with biologicals have put more emphasis on markers of Th2 disease irrespective of the presence of nasal polyps. The first type 2 targeting biologic anti- IL4R $\alpha$ (Dupilumab) has entered the market for CRSwNP patients and others like, anti-IgE, anti-IL5 and anti-IL5R $\alpha$ may follow shortly. ${ }^{129-131}$ Cluster analysis of CRS has shown that CRSsNP and CRSwNP are not dichotomous but instead have overlapping inflammatory signatures with type 2 inflammation as the predominant endotype mainly in CRSwNP but also CRSsNP especially in western parts of the world. Interestingly, some patients with CRS express a mixture of two or more inflammatory endotypes. ${ }^{22,132,133}$ The recently published EPOS2020 proposes a new clinical classification based on the disease being localized (often unilateral) or diffuse (always bilateral). Both these groups can be further divided into Th2 or non-Th2 disease. $^{4}$

In the very near future, it may be possible to offer personalized medicine for CRS patients where treatment is based on molecular biomarkers for the endotype or sub-endotype activated in an individual patient. ${ }^{27,134}$ The major challenge is to find reliable biomarkers that define Th2 inflammation and predict reaction to treatment. Ideally, these biomarkers should be supported by a body of evidence clarifying the biological significance, be quantifiable in a cost-efficient way and be easily measurable, preferably in blood or nasal secretion. ${ }^{14}$ Potential biomarkers could be eosinophils, neutrophils, ${ }^{135,136} \mathrm{IgE},{ }^{137} \mathrm{Th} 2$ cytokines, ${ }^{138}$ innate (epithelial) cytokines, ${ }^{111,137,139}$ but also phenotypical phenomena like smell loss, ${ }^{140}$ asthma and response to systemic corticosteroids. ${ }^{134}$ Contrary to FeNO in asthma, nasal NO has not been shown to be helpful to identify the T2 endotype because the main source of production of nasal NO are the sinuses that are closed off when CRS occurs. ${ }^{141}$ The main biomarkers used at the moment to define Th2 disease are eosinophils, IgE levels, and in some more specialized centres periostin and/or IL-5. There is quite some evidence showing that tissue and blood eosinophils are a reasonable surrogate marker for Th2 disease, and that blood 
eosinophils are a reasonable biomarker to predict eosinophilic CRS with or without nasal polyps. ${ }^{133}$ On the other hand, low tissue and serum eosinophilia, and absence of tissue squamous metaplasia may predict a CRS phenotype suitable for a trial of long-term macrolide therapy when surgery and topical therapy has failed. ${ }^{142}$ Unfortunately, recent large studies with monoclonal antibodies directed to Type 2 endotypes have not found reliable biomarkers to predict response to treatment. ${ }^{129,130,143-145}$ As in asthma, ${ }^{8}$ we need large, maybe real-life studies to find better predictors to identify responders to biological treatments. For now, our treatment decisions still heavily rely on phenotypical characteristics like smell loss, asthma, and response to surgery and systemic corticosteroids. ${ }^{4,27}$

\section{Biomarkers in food allergy}

Apart from clinical determinants of food allergy and the respective gold standard, the oral food challenge, biomarkers represent an area of extensive research. In food allergy the focus is on genetic risk factors, allergen-specific and non-specific humoral and cellular biomarkers. ${ }^{146-148}$

Although genetic markers for food allergy are not yet at the level of clinical relevance, genes linked to HLA-genes, and more importantly to epithelial integrity and consequently reduced barrier function like filaggrin, SPINK5, ${ }^{149}$ and SERPINB7, are linked to eczema development and also food allergy. ${ }^{150-156}$ Given the importance of the exposome in allergy development, epigenetics may even play a more important role. Promising results in the context of peanut allergy await replication in larger cohorts. ${ }^{157,158}$ Regulation at another level has been linked to the microRNA 193a-5p. It is involved in the post-transcriptional regulation of IL-4 and downregulated in PBMCs from milk allergic children. ${ }^{159}$ Due to the importance of barrier (dys)function in atopic diseases ${ }^{160-162}$ measurement of skin integrity may be a very important tool to identify high risk populations. Electrical impedance spectroscopy, successfully tested in rodents, may be capable of assessing this biomarker also in humans. ${ }^{163}$

Allergen extract-based testing methodologies like skin prick test (SPT) and/or specific IgE (sIgE) tend to over-diagnose food allergy. Thus, more specific approaches focusing on specific allergens (see Section on allergens) and epitope-specific antibody response patterns are explored. ${ }^{164}$ Diversity of IgE-binding to linear epitopes correlated with the severity of peanut and milk allergy ${ }^{165-167}$ and IgG4 and IgE antibody binding to specific milk epitopes was stronger and more diverse in children who do not outgrow their milk allergy. ${ }^{166}$ By measuring IgE and IgG4 responses with bead-immobilized milk epitopes and applying machine learning approaches, non-reactivity to baked milk could be predicted twice as successful as by conventional approaches. ${ }^{168-170}$ The soluble high affinity IgE receptor (FcERI) may also act as a biomarker for IgE mediated pathologies in a less allergen independent way. ${ }^{171}$

Although allergen specific T-cells are extremely rare, they display a pronounced Th2 type in allergic individuals. ${ }^{172,173}$ A subset of allergen-specific memory Th2 cells called $\mathrm{T}_{\mathrm{H}} 2 \mathrm{a}$ cells, which are $\mathrm{CD} 45^{+} \mathrm{CD} 27^{-} \mathrm{CD} 45 \mathrm{RB}^{-} \mathrm{CRTH} 2^{+} \mathrm{CD} 161^{+} \mathrm{CD} 49^{+}$, has been discovered. They are almost exclusively found in allergic individuals, secrete IL-5 and IL-9 and within that group the percentage of type 2 cytokine double, triple, or quadruple positive cells is higher compared to Th2 cells. Moreover, mRNA expression of IL-25-, IL-33- and TSLP-receptors is higher. ${ }^{174}$

Our understanding of B-cell regulation has significantly evolved over the last few years. ${ }^{175}$ Evidence is pointing towards an extreme rarity of IgE memory B-cells in peripheral blood of allergic individuals which may be absent in non-peanut allergic individuals. ${ }^{176}$ New therapeutic and diagnostic options opened up from data on allergen specific monoclonal antibodies that were generated via single-cell sorting of allergenspecific memory B-cells. ${ }^{177,178}$ B-cell IgE antibody mutational maturation has been associated with barrier dysfunction. ${ }^{179}$ Recently, the co-emergence of short lived IgE plasmablasts and IgG memory B-cells early in grass AIT in the absence of memory IgE+ B-cells has been reported. ${ }^{180,181}$ Both subsets shared clonotypes supporting the existence of pools of specific B-cell subsets e.g. from IgG1 positive allergen specific B-cells upon switch factors and stimulation as demonstrated in mice. ${ }^{180,182}$ Yet many questions on the emergence of IgE producing cells and their regulation have to be answered and new biomarkers in this context will arise.

Functional tests that simulate allergen exposure in vitro like the basophil activation test (BAT) offer the 
possibility to assess allergen induced IgE crosslinking. The BAT suggests adding significant diagnostic value to IgE based test methods. ${ }^{183-185}$ Promising results on the usage of passive sensitization strategies, mast-cell lines ${ }^{186}$ or pre-cursors ${ }^{187}$ have been reported.

There is still a significant need to develop biomarkers to diagnose and predict anaphylaxis to prevent near fatalities and fatalities. ${ }^{188,189}$ Beyond tryptase, which can be a very good marker in the emergency setting when baseline values exist ${ }^{76,190}$ predictors of life threatening reactions which can be measured on a routine basis or in multi-center trials are still missing.

There is the hope that the expanding array of novel mechanistic and diagnostic biomarkers provide the toolkit to develop algorithms or machine learning approaches to diagnose food allergy and predict treatment outcomes (Figure 5).

\section{Biomarkers in drug hypersensitivity}

Drug hypersensitivity reactions include those mediated by a specific immunological mechanism and those non-specific immune mediated (Figure 6). ${ }^{191}$

\section{Immunologically-mediated specific reactions}

These reactions are classified into immediate reaction (IR) and non-immediate reactions (NIRs) depending on whether they occur within 1-6 hours or later after the drug intake. The first group is mostly associated with an IgE-mediated mechanism and the latter with a T-cell dependent type. ${ }^{191,192}$

Skin tests (STs) are useful biomarkers for IRs to beta-lactam (BL) $\cdot{ }^{14,191-194}$ However, their sensitivity based on the classical antigenic determinants has decreased over the last decades ${ }^{195}$ possibly due to the changing patterns of consumption (e.g. amoxicillin-clavulanic acid is replacing penicillin). ${ }^{193}$ Interestingly, one antigenic determinant recognized by most patients with confirmed reactions to clavulanic acid has been recently identified. ${ }^{196}$ Therefore, amoxicillin and any suspected BL must be included when performing STs. ${ }^{192,195,197,198}$ For other drugs and for NIRs, the value of STs is very limited. ${ }^{14,192,193,199}$

Regarding in vitro tests, during the acute phase of the reaction, serum tryptase is the most valuable biomarker for confirming mast cell activation in IR. ${ }^{191}$ The expression of granzyme B and granulysin in blood cells may be useful for detecting lymphocyte activation in severe NIR. ${ }^{200}$ At the resolution phase, immunoassays are used in IRs to determine sIgE, although the sensitivity is lower than for STs $191,201,202$ and only commercially available for limited drugs. For BLs, it shows a variable sensitivity $(0-50 \%),{ }^{191,192,201}$ with the possibility of inducing false positive results when testing for Penicillin-V. ${ }^{203}$ The value of BAT in IR has been proven for BL and quinolones, giving a sensitivity up to $55 \%{ }^{204,205}$ and $83 \%,{ }^{199,206}$ respectively. The sensitivity of both sIgE and BAT correlates with severity reaction ${ }^{201}$, decreases with time, ${ }^{205,207}$ and depends on the activation basophil marker assessed, e.g. the detection of CD203c increases BAT sensitivity although remaining low $(36.4 \%) \cdot{ }^{206,208}$

The value of lymphocyte transformation test (LTT) in NIRs has shown to be unsatisfactory. ${ }^{14,191}$ The Tim3/galectin-9 axis functions as a checkpoint inhibitor for Th1 cells. Interestingly, Th1 cells and dendritic cells of patients with drug-induced maculopapular exanthema expressed lower levels of Tim3/galectin-9 at baseline compared with tolerant individuals. ${ }^{209}$ This observation might help identify subjects at risk of NIRs.

\section{Immunologically-mediated non-specific reactions}

The most important group in this type of reactions is cross-intolerance to NSAIDs (CI),${ }^{210,211}$ in which patients react to NSAIDs from different pharmacological groups related to its COX-1 inhibitory activity. ${ }^{191,210}$ CI has been classically divided into phenotypes with exclusive skin involvement (NSAIDs-exacerbated cutaneous disease (NECD) and NSAIDs-induced urticarial-angioedema (NIUA)) or with exclusive respiratory involvement (NSAIDs-exacerbated respiratory disease, NERD) ${ }^{28}$ Nevertheless, novel data indicate that almost $30 \%$ of patients with CI can experience blended reactions, especially involving skin and airways. ${ }^{212}$ Genetic predisposition might account for the burden of some CI phenotypes (e.g. variants of GNAI2 in NIUA) (Figure 7). ${ }^{213}$ 
As the underlying mechanism is related to arachidonic acid metabolism, potential biomarkers focus on determining leukotriene and prostaglandin metabolites. Therefore, urinary LTE4 has been reported as a useful biomarker to distinguish between different sub-phenotypes in NERD, ${ }^{214}$ between NERD and aspirintolerant asthma ${ }^{214}$ and phenotypes with skin involvement (NIUA and NECD) ${ }^{215}$ Sensitivity and specificity of urinary LTE4 for identifying NERD has been reported to range from 0.55-0.81 and 0.77-0.82, respectively, which depends on the detection method used. ${ }^{216}$ Serum LTE4 and LTE4/PGF2 ratio have also been reported as potential in vitro biomarkers for NERD ${ }^{217}$ and urinary PGF2 for NIUA and NECD (Table 1). ${ }^{215}$

Table 1

\begin{tabular}{|c|c|c|}
\hline Biomarker & Disease & Reference \\
\hline LTE4 & Aspirin-sensitivity in asthma & 216,217 \\
\hline LTE4/PGF2 ratio & Aspirin-sensitivity in asthma & 217 \\
\hline LTE4 and PGF2 & NIUA and NECD & 21 \\
\hline Tryptase & $\begin{array}{l}\text { Acute phase of IgE mediated } \\
\text { reactions }\end{array}$ & 191,201 \\
\hline Skin tests & $\begin{array}{l}\text { Immediate and Non-immediate } \\
\text { reactions to drugs }\end{array}$ & 193 \\
\hline Specific IgE & $\begin{array}{l}\text { Immediate reactions to } \\
\text { betalactams }\end{array}$ & 202 \\
\hline Basophil activation & $\begin{array}{l}\text { Immediate reactions to } \\
\text { betalactams Immediate reactions } \\
\text { to FQ }\end{array}$ & 204,206 \\
\hline \multirow{2}{*}{$\begin{array}{l}\text { lymphocyte transformation test } \\
\text { granzyme B and granulysin }\end{array}$} & Non immediate reactions & 201 \\
\hline & Stevens-Johnson syndrome & 200 \\
\hline
\end{tabular}

\section{Biomarkers in immune monitoring of allergen-specific immunotherapy}

Allergen immunotherapy (AIT) is the only therapy that can alter the natural course of immune responses to specific allergens, directing it towards desensitization and perhaps, towards tolerance. Routes of AIT include subcutaneous (SCIT), sublingual (SLIT), oral (OIT), or epicutaneous (EPIT). ${ }^{218}{ }^{219}$ Licensed products are available for therapy of AR, allergic asthma, stinging insect hypersensitivity, AD. ${ }^{220-225}$ AIT for food allergy is currently investigational, however, phase 3 trials are promising. ${ }^{226}$ Current evidence indicates that immunological changes associated with AIT differ from permanent tolerance as in healthy non-allergic individuals. AIT-acquired desensitization is often temporary, waning with time, but can be maintained with regular exposure to the allergen. ${ }^{219}$

Biomarkers that can identify responders, monitor treatment, predict durability of desensitization, and determine adverse event risk would aid clinical decisions and delivery of targeted and effective treatment. With the advent of data-driven "-omic" technologies, more potential biomarkers have been identified. ${ }^{227}$ Here, we briefly review the more promising candidates that are being evaluated for immune monitoring with an expanded number in Figure 8. ${ }^{228}$

Specific IgE and $\operatorname{Ig} G$

With the discovery of $\operatorname{IgE}$ in the 1960s, measurements of $\operatorname{IgE}$ have been a first step in diagnosis for atopic diseases. Both allergen-specific $\operatorname{IgE}(\mathrm{sIgE})$ and total $\operatorname{IgE}$ levels increase during the initial stages of AIT and subsequently decrease, ${ }^{229}$ however, decreases may not accompany a positive clinical outcome. ${ }^{230} \mathrm{Nu}-$ merous studies indicate IgG1 and IgG4 levels increase with therapy but do not always differentiate between responders and non-responders. IgG4 increases during AIT may reflect compliance not clinical efficacy. ${ }^{230}$ sIgG4 is purported to be a blocking antibody by competing for allergen binding with IgE bound to Fce receptors on mast cells and basophils, preventing degranulation. IgA and other subclasses of IgG may have similar blocking function. ${ }^{231}$ Recent data support skewing towards IgG2 and IgG4 subclasses after SLIT for 
temperate grass pollen. ${ }^{181}$ The IgG4/IgE ratio may monitor AIT progress and outcome, but has demonstrated conflicting utility. ${ }^{232-234}$ Flow cytometry-based assay (IgE-FAB) and a solid-phase assay enzymelinked immunosorbent-facilitated antigen binding (ELIFAB) assay can determine IgE-inhibitory activity. Although robust with good clinical efficacy correlation for AIT, these technologies are complex with usage limited to specialized centers. ${ }^{230,235,236}$

\section{Immunophenotyping of immune cells}

Allergic sensitization is associated with multiple changes in blood immune cells, ${ }^{175}$ and high dimensional immunophenotyping using flow- and mass spectrometry (i.e. Cytometry Time of Flight; CyTOF) has contributed greatly to this identification. ${ }^{237} \mathrm{~A}$ study on bee venom AIT provided detailed characterization of allergen-specific B cells before and after bee venom tolerance in allergic patients and bee-keepers with Api m 1 -specific B cells showing increased CCR5 expression after high-dose allergen exposure. ${ }^{238}$ In a study of OIT for milk allergy, researchers found, using flow cytometry, a significant increase in blood invariant natural killer cells and a shift from a type 2 T-helper (Th-2; i.e. IL-4, IL-13) to a Th-1 (ie IFN- $\gamma$ ) cytokine profile. ${ }^{239}$ Similar studies in other immunotherapy models can assist with determining potential biomarkers for monitoring AIT.

Recent evidence shows that AIT modulates the balance between circulating T follicular helper (Tfh) and regulatory cells (Tfr), with Tfr as a potential biomarker for AIT efficacy. ${ }^{240,241}$ Upregulation of the activated allergen-specific Tregs and downregulation of dysfunctional allergen-specific Treg cell subset, associated with improved clinical response, were recently described. ${ }^{242}$ Responder status was shown to be associated with increased frequency of IgA- and IgG4-expressing allergen specific B cells, plasmablasts, and IL-10+ and/or IL-1RA + Breg cells. ${ }^{243}$

AIT-induced T regulatory cells secreting IL-35 (iTR35) cells promote production of IL-10 from CD19+ B cells, Breg subsets and Tfr cells. ${ }^{24}$ Circulating Tfr cells share properties of memory cells and are distinct from their lymph nodes (LN) counterpart as they suppress B and Tfh cells with a much lower capacity, while circulating memory-like Tfh cells are more potent than LN effector Tfh cells. ${ }^{245}$ In addition, circulating memory-like Tfr cells persist for long periods, thus they could support the long-term immunomodulatory effect of peptide AIT. Functional evaluation of T regulatory cells via expression of Glycoprotein A repetitions predominant (GARP) and Special AT-rich sequence binding protein 1 (SATB1) is also interesting as a future potential biomarker. Tregs uniquely express GARP on their cell surface and GARP functions as a delivery system for latent TGF- $\beta$, which might augment the immunosuppressive role of Tregs on effector cells. ${ }^{246}$ GARP expression was described as an activation marker of parasitic infection induced Tregs that strongly suppress allergic inflammation, thus is a novel potential mechanistic pathway for AIT. SATB1 is a genome organizer protein expressed in a lineage specific manner in CD4+ T-cells. During the early Th2 cell differentiation, IL-5 expression is repressed through direct binding of SATB1 to the IL-5 promoter. Thus, SATB1 modulation might expand the impact of AIT on eosinophilic inflammation. In addition, SATB1dependent Treg-cell specific super-enhancers activation is crucial for Treg cell lineage specification in the thymus

\section{Basophil activation test}

Blood basophils express high levels of FceRI that have bound IgE. To determine sensitization, basophils are incubated in vitro with allergen, followed by examination of degranulation. Fusion of granules to the cell membrane leads to upregulation of surface markers CD63 and CD203c, which are indicative of specific IgE functional activity. In patients with AR undergoing SLIT, basophil activation decreased with clinical efficacy. ${ }^{247}$ Similar decreases occurred in patients undergoing peanut immunotherapy. ${ }^{234}$ However, in grass pollen SLIT, basophil activation did not correlate with clinical efficacy (Table 2). ${ }^{248}$

\section{Soluble cytokines}

With immunotherapy, there is redirection of Th2 phenotype towards a Th1 and Treg phenotype with decreases in Th2 cytokines (eg, IL-4, IL-19 13, IL-9) and upregulation of Th1 (eg, IFN $\gamma$ ), and regulatory 
cytokines (eg, TGF $\beta$ and IL-10). ${ }^{181,249}$ However, serum cytokine measurements are challenging due to low levels, which are often below the detection limit of current methods. ${ }^{230}$ Changes in cytokine production by CD4 T cells following AIT are assessable throughin vitro stimulation of PBMC from patients using allergen extracts, both at the protein and the transcript level. In T-cell of patients with HDM allergy, high levels of IL10 transcripts predicted immunotherapy success. ${ }^{250}$

Epigenetic biomarkers

Beyond cells, proteins and transcripts, epigenetic biomarkers may suggest prognosis. ${ }^{251,252}$ DNA methylation of promoter regions is associated with gene silencing, and FOXP3 gene expression is in part controlled through this. FoxP3 is the master regulator of Treg cells, and Syed et al found that peanut OIT resulted in hypomethylation of FOXP3 , indicating increased gene expression with immunotherapy. ${ }^{253}$

In conclusion, technological advances inform novel methods for monitoring immune responses with increased sensitivity and specificity. Studies indicate dysregulation of a number of molecular markers with AIT. Detection method optimization continues and should facilitate precision immunotherapy.

Table 2

\begin{tabular}{|c|c|c|c|}
\hline Immune cell type & Biomarkers & Assay & References \\
\hline Basophils & $\begin{array}{l}\text { Decrease in basophil } \\
\text { activation post } \\
\text { allergen-specific OIT } \\
\text { (CD63, CD203, } \\
\text { histamine release) }\end{array}$ & BAT, iBAT & $254-256$ \\
\hline B cells & $\begin{array}{l}\text { Induction of Breg cells on } \\
\text { AIT, Serological } \\
\text { readouts: food, and } \\
\text { allergen-specific IgE, } \\
\text { IgG4 Epitope-specific IgE } \\
\text { and IgG4 }\end{array}$ & $\begin{array}{l}\text { Flow cytometry, } \\
\text { ImmunoCAP, Eptiope } \\
\text { mapping }\end{array}$ & $170,234,243,257$ \\
\hline $\mathrm{T}$ cells & $\begin{array}{l}\text { Functional changes in } \\
\text { tetramer } \\
\text { positive/CFSElo/CD69+ } \\
\text { CD40L+ allergen-specific } \\
\text { CD4+ T cells, Tracking } \\
\text { Th2A cells Decrease in } \\
\text { T-cell derived type } 2 \\
\text { cytokines Epigenetic } \\
\text { changes in T cell subsets } \\
\text { (Tregs) }\end{array}$ & $\begin{array}{l}\text { Flow and mass } \\
\text { cytometry, } \\
\text { Luminex/ELISA, } \\
\text { pyrosequencing }\end{array}$ & $258-263$ \\
\hline Dendritic cells & $\begin{array}{l}\text { Changes in costimulatory } \\
\text { potential (CD80, CD } 86)\end{array}$ & $\begin{array}{l}\text { Flow cytometry, DC-T } \\
\text { cell co-culture }\end{array}$ & 253,264 \\
\hline
\end{tabular}

\section{SIgE as biomarker in food allergy}

Accurate diagnoses are essential for the management of food allergies. ${ }^{147}$ They depend on detailed clinical history, objective markers of sensitization and double-blind placebo-controlled food challenges (DBPCFC). ${ }^{265}$ These are time-consuming, require specialized medical facilities, and side effects may occur. Consequently, molecular allergy diagnosis aims to reveal significant associations between sIgE and clinical phenotypes.

Peanut 
A retrospective study of 205 peanut-challenged Danish patients found the best correlation between sIgE and clinical thresholds for the $2 \mathrm{~S}$ albumin Ara $\mathrm{h} 2 .{ }^{266} \mathrm{~A}$ diagnostic model for peanut allergy predicted the food challenge outcome with $100 \%$ accuracy in $59 \%$ versus Ara h 2 in $50 \%$ of 100 Danish peanut-allergic patients. ${ }^{267}$ Co-sensitization to Ara h 2 and 6 was associated with severe allergy in peanut-challenged Finnish patients. ${ }^{268}$ A French study of 48 peanut allergic children found that Ara h 2 sIgE titers could predict the risk of anaphylaxis. ${ }^{269}$

Soy

The cupins Gly $\mathrm{m} 5$ and 6 were suggested as markers for severe allergic reactions in 30 soy-allergic European patients. ${ }^{270} \mathrm{~A}$ high diagnostic value of the $2 \mathrm{~S}$ albumin Gly $\mathrm{m} 8$ was reported in soybean-sensitized Japanese children with and without symptoms. ${ }^{271}$ Gly $\mathrm{m} 8$ had an $\mathrm{AUC}=0.75$ for soy allergy while the values for Gly $\mathrm{m} 5$ and 6 were 0.69 and 0.64 , respectively. In a study on soy allergy diagnostics, Gly $\mathrm{m} 8$ had the highest AUC (0.79), comparable to skin prick test (0.76) and sIgE to soy extract (0.77) ${ }^{272}$ In this study, the cupins Gly $\mathrm{m} 5$ and 6 were related to mild symptoms.

Hazelnut

sIgE to the cupin Cor a 9 and the $2 \mathrm{~S}$ albumin Cor a 14 was strongly associated with clinical symptoms in 161 Dutch hazelnut-sensitized patients. ${ }^{273} \mathrm{sIgE}$ to Cor a 9 and 14 allowed correct diagnosis of $90 \%$ of severely hazelnut-allergic Belgian children. ${ }^{274}$ In 423 hazelnut-allergic patients, Cor a 9 and 14 were associated with severe symptoms $(\mathrm{AUC}=0.70) .{ }^{275} \mathrm{~A}$ model combining clinical symptoms and $\mathrm{sIgE}$ to Cor a 14 and walnut increased the AUC to 0.91. In a prospective multicenter study of 90 peanut and 44 hazelnut-allergic German children, a $90 \%$ probability for a positive food challenge was calculated for Ara h 2 -specific IgE at $14.4 \mathrm{kU} / \mathrm{L}$ and for Cor a 14-specific $\operatorname{IgE}$ at $47.8 \mathrm{kU} / \mathrm{L} .^{276}$

\section{Walnut}

sIgE to the $2 \mathrm{~S}$ albumin $\operatorname{Jug} r$ 1, the cupin Jug r 2, and the nsLTP1 Jug r 3 (AUC=0.79, 0.70, 0.62, resp.) predicted anaphylaxis in 45 walnut-allergic children. ${ }^{277}$ In 91 walnut-allergic subjects from Switzerland, Germany and Spain, severe reactions correlated with higher sIgE levels to Jug r 1 and the cupin Jug r $4 .{ }^{278}$ sIgE to Jug r $1(\mathrm{AUC}=0.79)$ from 32 walnut-allergic Korean children better discriminated clinical walnut allergy from tolerance than $\mathrm{sIgE}$ to walnut extract $(\mathrm{AUC}=0.56) .{ }^{279}$ In 34 peanut-, hazelnut- or walnutallergic Italian children, sIgE to Ara h 1 and Ara h 2, Cor a 9 and particularly Cor a 14, or Jug r 1, 2 and 3 was associated with anaphylaxis. ${ }^{280}$

\section{Cashew}

In 63 cashew-allergic Greek children, sIgE to the $2 \mathrm{~S}$ albumin Ana o 3 ( $\mathrm{AUC}=0.97)$ performed better than extracts for predicting cashew allergy. ${ }^{281} \mathrm{~A}$ markedly greater risk of a positive food challenge was observed for higher levels of sIgE to the cupins Ana o 1 and 2, and to Ana o 3 in 173 Dutch children with suspected cashew nut allergy. ${ }^{282}$ Ana o 3 discriminated between allergic and tolerant children better than extract-specific IgE with an $\mathrm{AUC}=0.94$ versus 0.78 . A $95 \%$ probability for a positive cashew challenge was estimated for Ana o 3 -sIgE at $2.0 \mathrm{kU} / \mathrm{L} .{ }^{283}$

\section{Egg and shrimp}

sIgE to the ovomucoid Gal d 1 correlated with an increased risk of persistent egg allergy. ${ }^{284}$ Sensitization to tropomyosin and sarcoplasmic calcium-binding protein was associated with clinical reactivity in 58 shrimpallergic patients. ${ }^{285}$

\section{Non-food}

Studies associating sIgE to allergens from multi-allergen non-food sources to clinical phenotypes are less in number. A study onArtemisia pollen allergy of 240 Chinese patients found that patients sensitized to three or four allergens had a higher risk of allergic asthma $(56.4 \%)$ than patients sensitized to two or one $(31.1 \%) .{ }^{286}$ Distinct sensitization patterns of 159 patients to dog, cat and horse allergens were associated with 
specific respiratory symptoms. ${ }^{287}$ Polysensitization to several house-dust mite allergens predicted current mite-related allergic rhinitis and current or future asthma. ${ }^{288}$

In conclusion, severe reactions to legume seeds and tree nuts are predominantly caused by sensitization to storage proteins rather than by pollen-related allergens such as Bet $\mathrm{v} 1$ or profilin homologues, or nsLTPs (Table 3).

Table 3 : Specific IgE to these allergens is associated with severe symptoms

\begin{tabular}{|c|c|c|c|c|c|c|}
\hline $\begin{array}{l}\text { Allergen } \\
\text { source }\end{array}$ & $2 \mathrm{~S}$ albumin & $\begin{array}{l}\text { Cupin } \\
*_{\text {vicilin-type }} \\
* * \text { legumin- } \\
\text { type }\end{array}$ & nsLTP1 & Ovomucoid & $\begin{array}{l}\text { Tropo- } \\
\text { myosin }\end{array}$ & References \\
\hline Peanut & $\begin{array}{l}\text { Ara h } 2 \text { Ara h } \\
6\end{array}$ & Ara h $1^{*}$ & & & & $266-269,280$ \\
\hline Soy & Gly $\mathrm{m} 8$ & $\begin{array}{l}\text { Gly } \mathrm{m} 5^{*} \text { Gly } \\
\mathrm{m} 6^{* *}\end{array}$ & & & & $270-272$ \\
\hline Hazelnut & Cora 14 & Cor a $9^{* *}$ & & & & $273-276,280$ \\
\hline Walnut & Jug r 1 & $\underset{4^{* *}}{\operatorname{Jug} \mathrm{r}} 2^{*}$ Jug $\mathrm{r}$ & Jug r 3 & & & $277,278,280$ \\
\hline Cashew & Ana o 3 & $\begin{array}{l}\text { Ana o } 1^{*} \text { Ana } \\
\text { o } 2^{* *}\end{array}$ & & & & $281-283$ \\
\hline Egg & & & & Gal d 1 & & 284 \\
\hline Shrimp & & & & & Lit $\mathrm{v} 4$ & 285 \\
\hline
\end{tabular}

\section{Biomarkers of the epithelial barrier}

Environmental factors, microbiome, epithelial cells and immune cells show a dynamic crosstalk at the skin and mucosal barriers in the development of AD, AR, CRS, eosinophilic esophagitis and asthma. ${ }^{162,289-294}$ Studies on the pathogenesis of these diseases have clearly demonstrated a barrier defect in the skin and involved mucosas and a systemic inflammation. ${ }^{293-296}$ Defects in the epithelial barriers, caused by both environmental risk factors and a genetic predisposition, may represent the starting point of a chronic inflammation and allergen sensitization. ${ }^{293-296}$ A significant number of studies have reported that environmental factors directly affect the barrier function of epithelium. ${ }^{150,297,298}$ In addition, T helper 2 cells, ILC2s and their cytokine IL-13 damage skin and lung barriers. ${ }^{293}{ }^{299}$ In addition mast cells and their enzyme chymase damage the epithelial barrier. ${ }^{300} 290$ The effects of environmental factors may, at least in part, be mediated by epigenetic mechanisms. Histone deacetylase activation by type 2 immune response has a major effect on leaky barriers and blocking of histone deacetylase activity corrects the defective barrier in human air-liquid interface cultures and mouse models of allergic asthma with rhinitis. ${ }^{95,293,301}$ The assessment of the barrier function of the skin and mucosas in vivo has an extremely high value in the clinics to identify barrier leakiness for an individual patient and requires the discovery of biomarkers.

To date, there were a few noninvasive methods to assess the skin epidermal barrier function in vivo. The quantification of transepidermal water loss (TEWL) in the skin across the stratum corneum had received some interest for early prediction of atopy prone children and detection of skin barrier. ${ }^{302}$ Although TEWL increases in proportion to the level of damage, it is also affected by environmental factors such as humidity, temperature, season and moisture content of the skin. ${ }^{303}$ The noninvasive and rapid measurement of natural moisturizing factor by Raman Spectroscopy provides a method suitable for use in children. The association of natural moisturizing factor, filaggrin null mutations and AD suggest Raman Spectroscopy as a promising approach for stratification of endotypes in $\mathrm{AD}$ in the clinics. Other noninvasive methods currently used include assessment of the stratum corneum hydration, colorimetry, skin surface $\mathrm{pH}$ and sebometry, but they only provide information on different characteristics and/or the condition of the skin and do not directly 
measure the barrier function. ${ }^{304}$

Recently, electrical impedance spectroscopy (EIS) has been identified as an effective and stable tool for the detection of epidermal barrier. ${ }^{163}$ This method works by transmitting a harmless electrical signal through the skin at several depths and frequencies and measuring the electrical resistance and impedance response of the tissue. EIS reflects particularly the tissue barrier status by collecting the electric impedance information from extracellular and intracellular tissue. ${ }^{305}$ Recently, our group has studied the impairment of the epidermal barrier in mice by the epicutaneous administration of barrier damaging proteases, such as papain, trypsin, Vibrio cholera toxin or by tape stripping. We were able to show the barrier damaging effects of these substances which correlates with the electric conductivity of the skin, causing a decrease of electrical impedance. According to these results, EIS shows a broad range of possible clinical applications in AD and atopic march, including early prediction of atopy prone children, early diagnosis of the disease, stratification and endotyping of patients, evaluation of the overall therapy response as well as single lesions and assessment of disease severity.

A critical feature of the gastrointestinal epithelium is intestinal barrier permeability as it must allow an efficient passage of nutrients while restricting the entry of larger molecules to avoid food allergy development. Multiple autoimmune diseases have been identified to arise or be exacerbated by a leaky gut, such as in inflammatory bowel disease, celiac disease, type 1 diabetes, systemic lupus erythematosus, multiple sclerosis. ${ }^{306-309}$ Recent studies point to a leaky gut as the initiator of type 1 diabetes because a subclinical intestinal barrier dysfunction was already detected before clinical onset of type 1 diabetes. ${ }^{310}$ Zonulin is a prehaptoglobulin protein and a biomarker for gut barrier leakiness that downregulates TJ function and it has been proposed to play a role in several autoimmune diseases. ${ }^{311}$

Translocation of bacterial endotoxin (lipopolysaccharide, LPS) from the gut microbiota to blood circulation stimulates systemic inflammatory responses. ${ }^{312}$ Measurement of intestinal permeability is often used in the examination of inflammatory gastrointestinal disorders. It can be assessed by measurement of urinary recovery of ingested non-metabolizable lactulose and mannitol. Urine L/M ratio measured by ${ }^{1} \mathrm{H}$ NMR spectroscopy showed high correlation with the standard measurement of the urinary recoveries by enzymatic assays. In conclusion, NMR metabolomics enables simultaneous intestinal permeability testing and discovery of biomarkers associated with an impaired intestinal permeability. ${ }^{313}$ In conclusion, identification of clinically reliable biomarkers for skin, respiratory and intestinal barrier measurements represent an important future research area.

\section{In vivo biomarkers in AIT development programs: European implications}

An increasing number of clinical trials in AIT have been published underlining both efficacy and safety of AIT as the only disease-modifying treatment option for patients with IgE-mediated respiratory allergic diseases. ${ }^{314}$ With country-specific exceptions, AIT products are regulated by Authorities such as the European Medicines Agency $^{315}$ and others on the basis of methodological guidelines.

In its guideline "Clinical Development of Products for Specific Immunotherapy for The Treatment of Allergic Diseases "315 the European regulatory authority, (European Medicine Agency (EMA)), has provided strict guidance for designing and performing clinical development programs in AIT. ${ }^{101,316}$ In Germany, these principles were followed in the "Therapy Allergen Ordinance (TAV)" for future registration of allergens and allergen-mixtures (derived from grass pollen, early flowering trees pollen, house dust mites, and bee and wasp venom) based on the main prevalent respiratory allergies in Germany. ${ }^{317-319}$ First registrations have been granted fulfilling the TAV demands by the German Paul Ehrlich Institut (PEI). ${ }^{320}$ Besides, a sufficient body of evidence exists in the clinical documentation of both SLIT and SCIT AIT products. ${ }^{321-323}$

An important unmet need for further harmonization of methodological principles in AIT study design ${ }^{324}$ has been followed in a series of Task-force initiatives of the European Academy of Allergy and Clinical Immunology (EAACI $)^{325}$ as overviewed in the 2019 report of our group. ${ }^{101}$ As such, position papers and guidelines on allergen-challenge procedures including clear standardization of procedures (SOPs) through the nasal ${ }^{326}$ or conjunctival ${ }^{327}$ route has been provided by the EAACI. 
In addition, the combined symptom and medication score (CSMS) as defined by the EAACI as standard primary endpoint for future (pivotal) trials in $\mathrm{AIT}^{328}$ has been recently used recently in an increasing number of key trials in AIT. ${ }^{329-331}$ However, further formal validation and amendments especially for the pediatric population are needed. ${ }^{320,332}$ As another example a further Task Force initiative aimed to provide clear clinically and aerobiologically justified definitions of pollen-counts for onset, peak and duration of pollenseasons $^{333}$ and those have been confirmed to be robust ${ }^{334}$ and clinically relevant as reflecting patients' symptom load in different countries in Europe in recent reports. ${ }^{334,335}$ Recently, the EAACI has published a Position Paper reporting the impact of the placebo effect in AIT from different methodological perspectives and outlining possible strategies to minimize this bias in clinical trials. ${ }^{336}$

Taken together, further emphasis should be put on international collaborations of clinical experts, methodologists and regulatory authorities to optimize methodological standards for AIT clinical development programs aimed to increase the level of evidence of AIT as the only disease-modifying therapy available. ${ }^{320,323,337}$

\section{Biomarkers on the clinical usage of biologicals in the EAACI}

The EAACI recently published the Guidelines on the use of biologicals in severe asthma. Recommendations were formulated following the GRADE approach ${ }^{338-340}$ for each biological (benralizumab, dupilumab, mepolizumab, omalizumab, reslizumab) and each outcome (decrease in asthma exacerbations, oral and inhaled corticosteroids and rescue medication use; improvement in asthma control, quality of life and lung function; and, safety). ${ }^{33}$ The recommendations were informed by 3 systematic reviews. ${ }^{341-343}$ FeNO, sputum and blood eosinophils were scored as outcomes with low importance, however the evidence was analysed for subgroups based on biomarkers and co-morbidities. The higher the blood eosinophils the higher the expected impact of benralizumab, dupilumab and mepolizumab in reducing severe asthma exacerbations. The improvement in asthma control was significantly better in the high eosinophil subgroup for benralizumab and reslizumab. Lung function increased significantly more in the high eosinophil subgroup for benralizumab, dupilumab and reslizumab. Benralizumab improved QoL better in the high eosinophil subgroup. The effect of omalizumab on exacerbations did not depend on blood eosinophils. Neither the atopic status or total $\operatorname{IgE}$ predict the magnitude of effect of benralizumab and serum $\operatorname{IgE}$ thresholds (within regulatory limits) did not influence the response to omalizumab (Table 4).

Table 4. Current biologicals, biomarkers, asthma outcomes and GRADE recommendation

Biological

Biological Asthma-related outcome Biomarkers Recommendation as per GRADE methodology Benralizumab Dupilumab R

\section{Conclusions}

In our discipline, a huge amount of omics research has been employed during recent years that needs to be analyzed in depth. Allergic diseases are a group of complex and heterogeneous diseases. Specific, sensitive and reliable (point-of-care) biomarkers are critical for selecting the proper treatment for the proper patient and enabling precision medicine. Precision endotyping is linking pathobiological mechanisms with visible properties via specific biomarkers. It is expected to be translated into pathway-specific diagnostic tests and opens a pathway to accurate disease classification and individualized targeted treatment options. We are expecting to change the diagnostic and therapeutic landscape in our specialty as well as of all medical disciplines. However, endotype-driven treatment still needs to face multiple challenges before its implementation in daily practice in allergic diseases and asthma. Most of the disease endotyping research is conducted in severe forms of allergic diseases nowadays. Over the past few years, the biomarker discovery field has gained great advances, which facilitates the identification of novel methods for disease diagnosis and therapy. With these fast-growing efforts, we can imagine that in the near future, we will be able to find better ways to treat allergic diseases, with a therapeutic approach targeted to the individual patient.

\section{References}


1. Galli SJ, Tsai M, Piliponsky AM. The development of allergic inflammation. Nature. 2008;454(7203):445454.

2. Samitas K, Carter A, Kariyawasam HH, Xanthou G. Upper and lower airway remodelling mechanisms in asthma, allergic rhinitis and chronic rhinosinusitis: The one airway concept revisited. Allergy.2018;73(5):9931002 .

3. Barbarot S, Auziere S, Gadkari A, et al. Epidemiology of atopic dermatitis in adults: Results from an international survey. Allergy. 2018;73(6):1284-1293.

4. Fokkens WJ, Lund VJ, Hopkins C, et al. European Position Paper on Rhinosinusitis and Nasal Polyps 2020. Rhinology. 2020;58(Suppl S29):1-464.

5. De Meulder B, Lefaudeux D, Bansal AT, et al. A computational framework for complex disease stratification from multiple large-scale datasets. BMC systems biology. 2018;12(1):60.

6. Agache I, Sugita K, Morita H, Akdis M, Akdis CA. The Complex Type 2 Endotype in Allergy and Asthma: From Laboratory to Bedside. Curr Allergy Asthma Rep. 2015;15(6):29.

7. Agache I, Rogozea L. Asthma Biomarkers: Do They Bring Precision Medicine Closer to the Clinic? Allergy Asthma Immunol Res.2017;9(6):466-476.

8. Diamant Z, Vijverberg S, Alving K, et al. Toward clinically applicable biomarkers for asthma: An EAACI position paper.Allergy. 2019;74(10):1835-1851.

9. Agache I, Strasser DS, Klenk A, et al. Serum IL-5 and IL-13 consistently serve as the best predictors for the blood eosinophilia phenotype in adult asthmatics. Allergy. 2016;71(8):1192-1202.

10. Yii ACA, Tay TR, Choo XN, Koh MSY, Tee AKH, Wang DY. Precision medicine in united airways disease: A "treatable traits" approach.Allergy. 2018;73(10):1964-1978.

11. Bachert C, Zhang N. Medical algorithm: Diagnosis and treatment of chronic rhinosinusitis. Allergy. 2020;75(1):240-242.

12. Cardona V, Demoly P, Dreborg S, et al. Current practice of allergy diagnosis and the potential impact of regulation in Europe.Allergy. 2018;73(2):323-327.

13. Diamant Z, Vijverberg SJ, Agache I, et al. Much ado about Biologicals: Highlights of the Master Class on Biologicals, Prague, 2018. Allergy. 2019;74(4):837-840.

14. Eguiluz-Gracia I, Tay TR, Hew M, et al. Recent developments and highlights in biomarkers in allergic diseases and asthma.Allergy. 2018;73(12):2290-2305.

15. Guerra ENS, Acevedo AC, de Toledo IP, Combes A, Chardin H. Do mucosal biomarkers reveal the immunological state associated with food allergy? Allergy. 2018;73(12):2392-2394.

16. Chen LC, Tseng HM, Kuo ML, et al. A composite of exhaled LTB(4), LXA(4), FeNO, and FEV(1) as an "asthma classification ratio" characterizes childhood asthma. Allergy. 2018;73(3):627-634.

17. Rodrigo-Muñoz JM, Cañas JA, Sastre B, et al. Asthma diagnosis using integrated analysis of eosinophil microRNAs. Allergy.2019;74(3):507-517.

18. Siroux V, Boudier A, Nadif R, Lupinek C, Valenta R, Bousquet J. Association between asthma, rhinitis, and conjunctivitis multimorbidities with molecular IgE sensitization in adults. Allergy. 2019;74(4):824-827.

19. Lunjani N, Satitsuksanoa P, Lukasik Z, Sokolowska M, Eiwegger T, O’Mahony L. Recent developments and highlights in mechanisms of allergic diseases: Microbiome. Allergy. 2018;73(12):2314-2327.

20. Su MW, Lin WC, Tsai CH, et al. Childhood asthma clusters reveal neutrophil-predominant phenotype with distinct gene expression.Allergy. 2018;73(10):2024-2032. 
21. Dona I, Jurado-Escobar R, Perkins JR, et al. Eicosanoid mediator profiles in different phenotypes of nonsteroidal anti-inflammatory drug-induced urticaria. Allergy. 2019;74donm(6):1135-1144.

22. Liao B, Liu JX, Li ZY, et al. Multidimensional endotypes of chronic rhinosinusitis and their association with treatment outcomes.Allergy. 2018;73(7):1459-1469.

23. Asthma GIf. https://ginasthma.org/. accessed June 30, 2020.

24. Seys SF, Quirce S, Agache I, et al. Severe asthma: Entering an era of new concepts and emerging therapies: Highlights of the 4th international severe asthma forum, Madrid, 2018. Allergy.2019;74(11):2244-2248.

25. Kaur R, Chupp G. Phenotypes and endotypes of adult asthma: Moving toward precision medicine. The Journal of allergy and clinical immunology. 2019;144(1):1-12.

26. Fahy JV. Type 2 inflammation in asthma-present in most, absent in many. Nat Rev Immunol. 2015;15(1):57-65.

27. Fokkens WJ, Lund V, Bachert C, et al. EUFOREA consensus on biologics for CRSwNP with or without asthma. Allergy.2019;74(12):2312-2319.

28. Kowalski ML, Agache I, Bavbek S, et al. Diagnosis and management of NSAID-Exacerbated Respiratory Disease (N-ERD)-a EAACI position paper.Allergy. 2019;74(1):28-39.

29. Roth-Walter F, Adcock IM, Benito-Villalvilla C, et al. Comparing biologicals and small molecule drug therapies for chronic respiratory diseases: An EAACI Taskforce on Immunopharmacology position paper.Allergy. 2019;74(3):432-448.

30. Woodruff PG, Boushey HA, Dolganov GM, et al. Genome-wide profiling identifies epithelial cell genes associated with asthma and with treatment response to corticosteroids. Proceedings of the National Academy of Sciences of the United States of America.2007;104(40):15858-15863.

31. Alving K, Diamant Z, Lucas S, et al. Point-of-care biomarkers in asthma management: Time to move forward. Allergy.2020;75(4):995-997.

32. Holguin F, Cardet JC, Chung KF, et al. Management of severe asthma: a European Respiratory Society/American Thoracic Society guideline.Eur Respir J. 2020;55(1).

33. Agache I, Akdis C, Akdis M, et al. EAACI Biologicals Guidelines - Recommendations for severe asthma. Allergy. 2020.

34. Diamant Z, Boot JD, Mantzouranis E, Flohr R, Sterk PJ, Gerth van Wijk R. Biomarkers in asthma and allergic rhinitis. Pulm Pharmacol Ther. 2010;23(6):468-481.

35. McDowell PJ, Heaney LG. Different endotypes and phenotypes drive the heterogeneity in severe asthma. Allergy. 2020;75(2):302-310.

36. Sze E, Bhalla A, Nair P. Mechanisms and therapeutic strategies for non-T2 asthma. Allergy. 2020;75(2):311-325.

37. Taylor SL, Leong LEX, Choo JM, et al. Inflammatory phenotypes in patients with severe asthma are associated with distinct airway microbiology. The Journal of allergy and clinical immunology.2018;141(1):94103.e115.

38. Green BJ, Wiriyachaiporn S, Grainge C, et al. Potentially pathogenic airway bacteria and neutrophilic inflammation in treatment resistant severe asthma. PloS one. 2014;9(6):e100645.

39. Tliba O, Panettieri RA, Jr. Paucigranulocytic asthma: Uncoupling of airway obstruction from inflammation. The Journal of allergy and clinical immunology. 2019;143(4):1287-1294.

40. Wenzel SE. Asthma phenotypes: the evolution from clinical to molecular approaches. Nat Med. 2012;18(5):716-725. 
41. Agusti A, Bafadhel M, Beasley R, et al. Precision medicine in airway diseases: moving to clinical practice. Eur Respir J. 2017;50(4).

42. Chung KF, Adcock IM. Precision medicine for the discovery of treatable mechanisms in severe asthma. Allergy.2019;74(9):1649-1659.

43. Simpson AJ, Hekking PP, Shaw DE, et al. Treatable traits in the European U-BIOPRED adult asthma cohorts. Allergy.2019;74(2):406-411.

44. Lefaudeux D, De Meulder B, Loza MJ, et al. U-BIOPRED clinical adult asthma clusters linked to a subset of sputum omics. The Journal of allergy and clinical immunology. 2017;139(6):1797-1807.

45. Schofield JPR, Burg D, Nicholas B, et al. Stratification of asthma phenotypes by airway proteomic signatures. The Journal of allergy and clinical immunology. 2019;144(1):70-82.

46. Ivanova O, Richards LB, Vijverberg SJ, et al. What did we learn from multiple omics studies in asthma? Allergy. 2019;74(11):2129-2145.

47. Dunican EM, Elicker BM, Gierada DS, et al. Mucus plugs in patients with asthma linked to eosinophilia and airflow obstruction. The Journal of clinical investigation. 2018;128(3):997-1009.

48. Erjefalt JS. Unravelling the complexity of tissue inflammation in uncontrolled and severe asthma. Curr Opin Pulm Med.2019;25(1):79-86.

49. Walter J, O'Mahony L. The importance of social networks-An ecological and evolutionary framework to explain the role of microbes in the aetiology of allergy and asthma. Allergy.2019;74(11):2248-2251.

50. Savage JH, Lee-Sarwar KA, Sordillo J, et al. A prospective microbiome-wide association study of food sensitization and food allergy in early childhood. Allergy. 2018;73(1):145-152.

51. Kozik A, Huang YJ. Ecological interactions in asthma: from environment to microbiota and immune responses. Curr Opin Pulm Med. 2020;26(1):27-32.

52. Sokolowska M, Frei R, Lunjani N, Akdis CA, O’Mahony L. Microbiome and asthma. Asthma Res Pract. 2018;4:1.

53. Sbihi H, Boutin RC, Cutler C, Suen M, Finlay BB, Turvey SE. Thinking bigger: How early-life environmental exposures shape the gut microbiome and influence the development of asthma and allergic disease.Allergy. 2019;74(11):2103-2115.

54. Arrieta MC, Stiemsma LT, Dimitriu PA, et al. Early infancy microbial and metabolic alterations affect risk of childhood asthma. Sci Transl Med. 2015;7(307):307ra152.

55. Fujimura KE, Sitarik AR, Havstad S, et al. Neonatal gut microbiota associates with childhood multisensitized atopy and T cell differentiation. Nat Med. 2016;22(10):1187-1191.

56. Bannier M, van Best N, Bervoets L, et al. Gut microbiota in wheezing preschool children and the association with childhood asthma.Allergy. 2019.

57. Thorsen J, Rasmussen MA, Waage J, et al. Infant airway microbiota and topical immune perturbations in the origins of childhood asthma. Nat Commun. 2019;10(1):5001.

58. Zhou Y, Jackson D, Bacharier LB, et al. The upper-airway microbiota and loss of asthma control among asthmatic children. Nat Commun.2019;10(1):5714.

59. Huang YJ, Nariya S, Harris JM, et al. The airway microbiome in patients with severe asthma: Associations with disease features and severity. The Journal of allergy and clinical immunology.2015;136(4):874-884.

60. Michalovich D, Rodriguez-Perez N, Smolinska S, et al. Obesity and disease severity magnify disturbed microbiome-immune interactions in asthma patients. Nat Commun. 2019;10(1):5711. 
61. Roduit C, Frei R, Ferstl R, et al. High levels of butyrate and propionate in early life are associated with protection against atopy. Allergy. 2019;74(4):799-809.

62. Lewis G, Wang B, Shafiei Jahani P, et al. Dietary Fiber-Induced Microbial Short Chain Fatty Acids Suppress ILC2-Dependent Airway Inflammation. Front Immunol. 2019;10:2051.

63. Barcik W, Pugin B, Westermann P, et al. Histamine-secreting microbes are increased in the gut of adult asthma patients. The Journal of allergy and clinical immunology. 2016;138(5):1491-1494 e1497.

64. Barcik W, Pugin B, Bresco MS, et al. Bacterial secretion of histamine within the gut influences immune responses within the lung.Allergy. 2019;74(5):899-909.

65. Lee JJ, Kim SH, Lee MJ, et al. Different upper airway microbiome and their functional genes associated with asthma in young adults and elderly individuals. Allergy. 2019;74(4):709-719.

66. Jobin C. Precision medicine using microbiota. Science.2018;359(6371):32-34.

67. Maurer M, Hawro T, Krause K, et al. Diagnosis and treatment of chronic inducible urticaria. Allergy. 2019;74(12):2550-2553.

68. Bieber T, Traidl-Hoffmann C, Schäppi G, Lauener R, Akdis C, Schmid-Grendlmeier P. Unraveling the complexity of atopic dermatitis: The CK-CARE approach toward precision medicine. Allergy. 2020.

69. Venter C, Meyer RW, Nwaru BI, et al. EAACI position paper: Influence of dietary fatty acids on asthma, food allergy, and atopic dermatitis.Allergy. 2019;74(8):1429-1444.

70. Altunbulakli C, Reiger M, Neumann AU, et al. Relations between epidermal barrier dysregulation and Staphylococcus species-dominated microbiome dysbiosis in patients with atopic dermatitis. The Journal of allergy and clinical immunology. 2018;142(5):1643-1647 e1612.

71. Moriwaki M, Iwamoto K, Niitsu Y, et al. Staphylococcus aureus from atopic dermatitis skin accumulates in the lysosomes of keratinocytes with induction of IL-1 $\alpha$ secretion via TLR9. Allergy.2019;74(3):560-571.

72. Reiger M, Traidl-Hoffmann C, Neumann AU. The skin microbiome as a clinical biomarker in atopic eczema: Promises, navigation, and pitfalls. The Journal of allergy and clinical immunology.2020;145(1):9396.

73. Gokkaya M, Damialis A, Nussbaumer T, et al. Defining biomarkers to predict symptoms in subjects with and without allergy under natural pollen exposure. The Journal of allergy and clinical immunology.2020.

74. Gonzalez T, Stevens ML, Baatrebek Kyzy A, et al. Biofilm propensity of Staphylococcus aureus skin isolates is associated with increased atopic dermatitis severity and barrier dysfunction in the MPAACH pediatric cohort. Allergy. 2020.

75. Hülpüsch C, Tremmel K, Hammel G, et al. Skin pH-dependent Staphylococcus aureus abundance as predictor for increasing atopic dermatitis severity. Allergy. 2020.

76. Vitte J, Amadei L, Gouitaa M, et al. Paired acute-baseline serum tryptase levels in perioperative anaphylaxis: An observational study. Allergy. 2019;74(6):1157-1165.

77. Izuhara K, Nunomura S, Nanri Y, Ono J, Takai M, Kawaguchi A. Periostin: An emerging biomarker for allergic diseases. Allergy.2019;74(11):2116-2128.

78. Ando N, Nakamura Y, Ishimaru K, et al. Allergen-specific basophil reactivity exhibits daily variations in seasonal allergic rhinitis.Allergy. 2015;70(3):319-322.

79. Zhong H, Fan XL, Yu QN, et al. Increased innate type 2 immune response in house dust mite-allergic patients with allergic rhinitis. Clin Immunol. 2017;183:293-299.

80. Dhariwal J, Cameron A, Trujillo-Torralbo MB, et al. yuMucosal Type 2 Innate Lymphoid Cells Are a Key Component of the Allergic Response to Aeroallergens. Am J Respir Crit Care Med. 2017;195(12):1586-1596. 
81. Yu QN, Guo YB, Li X, et al. ILC2 frequency and activity are inhibited by glucocorticoid treatment via STAT pathway in patients with asthma. Allergy. 2018;73(9):1860-1870.

82. Tojima I, Matsumoto K, Kikuoka H, et al. Evidence for the induction of Th2 inflammation by group 2 innate lymphoid cells in response to prostaglandin D2 and cysteinyl leukotrienes in allergic rhinitis. Allergy. 2019;74(12):2417-2426.

83. Iinuma T, Okamoto Y, Morimoto Y, et al. Pathogenicity of memory Th2 cells is linked to stage of allergic rhinitis. Allergy.2018;73(2):479-489.

84. North ML, Jones MJ, MacIsaac JL, et al. Blood and nasal epigenetics correlate with allergic rhinitis symptom development in the environmental exposure unit. Allergy. 2018;73(1):196-205.

85. Cardenas A, Sordillo JE, Rifas-Shiman SL, et al. The nasal methylome as a biomarker of asthma and airway inflammation in children. Nat Commun. 2019;10(1):3095.

86. Panganiban RP, Wang Y, Howrylak J, et al. Circulating microRNAs as biomarkers in patients with allergic rhinitis and asthma. The Journal of allergy and clinical immunology. 2016;137(5):1423-1432.

87. Panganiban RP, Lambert KA, Hsu MH, Laryea Z, Ishmael FT. Isolation and profiling of plasma microRNAs: Biomarkers for asthma and allergic rhinitis. Methods. 2019;152:48-54.

88. Ma GC, Wang TS, Wang J, Ma ZJ, Pu SB. Serum metabolomics study of patients with allergic rhinitis. Biomed Chromatogr.2020;34(3):e4739.

89. Choi GS, Shin SY, Kim JH, et al. Serum lactoferrin level as a serologic biomarker for allergic rhinitis. Clin Exp Allergy.2010;40(3):403-410.

90. Bousquet J, Pfaar O, Togias A, et al. 2019 ARIA Care pathways for allergen immunotherapy. Allergy. 2019;74(11):2087-2102.

91. Reitsma S, Subramaniam S, Fokkens WWJ, Wang Y. Recent developments and highlights in rhinitis and allergen immunotherapy. Allergy.2018;73(12):2306-2313.

92. Kortekaas Krohn I, Callebaut I, Alpizar YA, et al. MP29-02 reduces nasal hyperreactivity and nasal mediators in patients with house dust mite-allergic rhinitis. Allergy. 2018;73(5):1084-1093.

93. Rittchen S, Heinemann A. Therapeutic Potential of Hematopoietic Prostaglandin D2 Synthase in Allergic Inflammation. Cells.2019;8(6).

94. Okubo K, Hashiguchi K, Takeda T, et al. A randomized controlled phase II clinical trial comparing ONO4053, a novel DP1 antagonist, with a leukotriene receptor antagonist pranlukast in patients with seasonal allergic rhinitis. Allergy. 2017;72(10):1565-1575.

95. Meng Y, Wang C, Zhang L. Recent developments and highlights in allergic rhinitis. Allergy. 2019;74(12):2320-2328.

96. Eyerich S, Metz M, Bossios A, Eyerich K. New biological treatments for asthma and skin allergies. Allergy. 2020;75(3):546-560.

97. Mukherjee M, Bakakos P, Loukides S. New paradigm in asthma management: Switching between biologics! Allergy.2020;75(4):743-745.

98. Tsabouri S, Tseretopoulou X, Priftis K, Ntzani EE. Omalizumab for the treatment of inadequately controlled allergic rhinitis: a systematic review and meta-analysis of randomized clinical trials. $J$ Allergy Clin Immunol Pract. 2014;2(3):332-340 e331.

99. Kopp MV, Hamelmann E, Bendiks M, et al. Transient impact of omalizumab in pollen allergic patients undergoing specific immunotherapy. Pediatr Allergy Immunol. 2013;24(5):427-433. 
100. Weinstein SF, Katial R, Jayawardena S, et al. Efficacy and safety of dupilumab in perennial allergic rhinitis and comorbid asthma. The Journal of allergy and clinical immunology.2018;142(1):171-177 e171.

101. Breiteneder H, Diamant Z, Eiwegger T, et al. Future research trends in understanding the mechanisms underlying allergic diseases for improved patient care. Allergy. 2019;74(12):2293-2311.

102. Murray CS, Poletti G, Kebadze T, et al. Study of modifiable risk factors for asthma exacerbations: virus infection and allergen exposure increase the risk of asthma hospital admissions in children. Thorax. 2006;61(5):376-382.

103. Akbarshahi H, Menzel M, Ramu S, Mahmutovic Persson I, Bjermer L, Uller L. House dust mite impairs antiviral response in asthma exacerbation models through its effects on TLR3. Allergy.2018;73(5):1053-1063.

104. Oliver BG, Robinson P, Peters M, Black J. Viral infections and asthma: an inflammatory interface? Eur Respir J.2014;44(6):1666-1681.

105. Johnston NW, Johnston SL, Duncan JM, et al. The September epidemic of asthma exacerbations in children: a search for etiology. The Journal of allergy and clinical immunology. 2005;115(1):132-138.

106. Hasegawa K, Hoptay CE, Harmon B, et al. Association of type 2 cytokines in severe rhinovirus bronchiolitis during infancy with risk of developing asthma: A multicenter prospective study. Allergy.2019;74(7):13741377.

107. Globinska A, Pawelczyk M, Piechota-Polanczyk A, et al. Impaired virus replication and decreased innate immune responses to viral infections in nasal epithelial cells from patients with allergic rhinitis. Clin Exp Immunol. 2017;187(1):100-112.

108. Jeon YJ, Lim JH, An S, et al. Type III interferons are critical host factors that determine susceptibility to Influenza A viral infection in allergic nasal mucosa. Clin Exp Allergy.2018;48(3):253-265.

109. Gilles S, Blume C, Wimmer M, et al. Pollen exposure weakens innate defense against respiratory viruses. Allergy. 2020;75(3):576-587.

110. Flayer CH, Haczku A. The Th2 gene cluster unraveled: role of RHS6.Allergy. 2017;72(5):679-681.

111. Hong HY, Chen FH, Sun YQ, et al. Local IL-25 contributes to Th2-biased inflammatory profiles in nasal polyps. Allergy.2018;73(2):459-469.

112. Tan KS, Andiappan AK, Lee B, et al. RNA Sequencing of H3N2 Influenza Virus-Infected Human Nasal Epithelial Cells from Multiple Subjects Reveals Molecular Pathways Associated with Tissue Injury and Complications. Cells. 2019;8(9).

113. Roan F, Obata-Ninomiya K, Ziegler SF. Epithelial cell-derived cytokines: more than just signaling the alarm. The Journal of clinical investigation. 2019;129(4):1441-1451.

114. Tan KS, Ong HH, Yan Y, et al. In Vitro Model of Fully Differentiated Human Nasal Epithelial Cells Infected With Rhinovirus Reveals Epithelium-Initiated Immune Responses. J Infect Dis.2018;217(6):906-915.

115. Becker Y. Respiratory syncytial virus (RSV) evades the human adaptive immune system by skewing the Th1/Th2 cytokine balance toward increased levels of Th2 cytokines and IgE, markers of allergy-a review. Virus Genes. 2006;33(2):235-252.

116. Malinczak CA, Rasky AJ, Fonseca W, et al. Upregulation of H3K27 Demethylase KDM6 During Respiratory Syncytial Virus Infection Enhances Proinflammatory Responses and Immunopathology. J Immunol.2020;204(1):159-168.

117. Scanlon ST, McKenzie AN. Type 2 innate lymphoid cells: new players in asthma and allergy. Curr Opin Immunol. 2012;24(6):707-712. 
118. Han JJ, Goldsmith AM, Hong JY, Sajjan U, Hershenson MB. Rhinovirus induces the expression of thymic stromal lymphopoietin in human airway epithelial cells. Am J Respir Crit Care Med. 2012;185:A6875.

119. Beale J, Jayaraman A, Jackson DJ, et al. Rhinovirus-induced IL-25 in asthma exacerbation drives type 2 immunity and allergic pulmonary inflammation. Sci Transl Med. 2014;6(256):256ra134.

120. Shaw JL, Fakhri S, Citardi MJ, et al. IL-33-responsive innate lymphoid cells are an important source of IL-13 in chronic rhinosinusitis with nasal polyps. Am J Respir Crit Care Med.2013;188(4):432-439.

121. Yan Y, Tan KS, Li C, et al. Human nasal epithelial cells derived from multiple subjects exhibit differential responses to $\mathrm{H} 3 \mathrm{~N} 2$ influenza virus infection in vitro. The Journal of allergy and clinical immunology. 2016;138(1):276-281 e215.

122. Jurak LM, Xi Y, Landgraf M, Carroll ML, Murray L, Upham JW. Interleukin 33 Selectively Augments Rhinovirus-Induced Type 2 Immune Responses in Asthmatic but not Healthy People. Front Immunol.2018;9:1895.

123. Tian T, Zi X, Peng Y, et al. H3N2 influenza virus infection enhances oncostatin M expression in human nasal epithelium. Exp Cell Res. 2018;371(2):322-329.

124. Li L, Chong HC, Ng SY, et al. Angiopoietin-like 4 Increases Pulmonary Tissue Leakiness and Damage during Influenza Pneumonia. Cell Rep. 2015;10(5):654-663.

125. Taka S, Tzani-Tzanopoulou P, Wanstall H, Papadopoulos NG. MicroRNAs in Asthma and Respiratory Infections: Identifying Common Pathways.Allergy Asthma Immunol Res. 2020;12(1):4-23.

126. Tiwari BS, Belenghi B, Levine A. Oxidative stress increased respiration and generation of reactive oxygen species, resulting in ATP depletion, opening of mitochondrial permeability transition, and programmed cell death. Plant Physiol. 2002;128(4):1271-1281.

127. Aizawa H, Koarai A, Shishikura Y, et al. Oxidative stress enhances the expression of IL-33 in human airway epithelial cells. Respir Res. 2018;19(1):52.

128. Manji J, Thamboo A, Tacey M, Garnis C, Chadha NK. The presence of Interleukin-13 in nasal lavage may be a predictor of nasal polyposis in pediatric patients with cystic fibrosis. Rhinology.2018;56(3):261-267.

129. Bachert C, Han JK, Desrosiers M, et al. Efficacy and safety of dupilumab in patients with severe chronic rhinosinusitis with nasal polyps (LIBERTY NP SINUS-24 and LIBERTY NP SINUS-52): results from two multicentre, randomised, double-blind, placebo-controlled, parallel-group phase 3 trials. Lancet. 2019;394(10209):1638-1650.

130. Bachert C, Sousa AR, Lund VJ, et al. Reduced need for surgery in severe nasal polyposis with mepolizumab: Randomized trial. The Journal of allergy and clinical immunology. 2017;140(4):1024-1031 e1014.

131. Bachert C, Zinreich SJ, Hellings PW, et al. Dupilumab reduces opacification across all sinuses and related symptoms in patients with CRSwNP. Rhinology. 2020;58(1):10-17.

132. Tomassen P, Vandeplas G, Van Zele T, et al. Inflammatory endotypes of chronic rhinosinusitis based on cluster analysis of biomarkers. The Journal of allergy and clinical immunology.2016;137(5):1449-1456 e1444.

133. Fokkens WJ, Reitsma S. Medical algorithms: Management of chronic rhinosinusitis. Allergy. 2019;74(7):1415-1416.

134. Xu X, Ong YK, Wang Y. Novel findings in immunopathophysiology of chronic rhinosinusitis and their role in a model of precision medicine.Allergy. 2020;75(4):769-780.

135. Arebro J, Drakskog C, Winqvist O, Bachert C, Kumlien Georen S, Cardell LO. Subsetting reveals CD16(high) CD62L(dim) neutrophils in chronic rhinosinusitis with nasal polyps. Allergy.2019;74(12):24992501. 
136. Succar EF, Li P, Ely KA, Chowdhury NI, Chandra RK, Turner JH. Neutrophils are underrecognized contributors to inflammatory burden and quality of life in chronic rhinosinusitis. Allergy.2020;75(3):713-716.

137. Jonstam K, Westman M, Holtappels G, Holweg CTJ, Bachert C. Serum periostin, IgE, and SE-IgE can be used as biomarkers to identify moderate to severe chronic rhinosinusitis with nasal polyps. The Journal of allergy and clinical immunology. 2017;140(6):1705-1708 e1703.

138. Zhang Y, Derycke L, Holtappels G, et al. Th2 cytokines orchestrate the secretion of MUC5AC and MUC5B in IL-5-positive chronic rhinosinusitis with nasal polyps. Allergy. 2019;74(1):131-140.

139. Ogasawara N, Klingler AI, Tan BK, et al. Epithelial activators of type 2 inflammation: Elevation of thymic stromal lymphopoietin, but not IL-25 or IL-33, in chronic rhinosinusitis with nasal polyps in Chicago, Illinois. Allergy. 2018;73(11):2251-2254.

140. Rouyar A, Classe M, Gorski R, et al. Type 2/Th2-driven inflammation impairs olfactory sensory neurogenesis in mouse chronic rhinosinusitis model. Allergy. 2019;74(3):549-559.

141. Rimmer J, Hellings P, Lund VJ, et al. European position paper on diagnostic tools in rhinology. Rhinology. 2019;57(Suppl S28):1-41.

142. Oakley GM, Christensen JM, Sacks R, Earls P, Harvey RJ. Characteristics of macrolide responders in persistent post-surgical rhinosinusitis. Rhinology. 2018;56(2):111-117.

143. Bidder T, Sahota J, Rennie C, Lund VJ, Robinson DS, Kariyawasam HH. Omalizumab treats chronic rhinosinusitis with nasal polyps and asthma together-a real life study. Rhinology. 2018;56(1):42-45.

144. Jonstam K, Swanson BN, Mannent LP, et al. Dupilumab reduces local type 2 pro-inflammatory biomarkers in chronic rhinosinusitis with nasal polyposis. Allergy. 2019;74(4):743-752.

145. Tsetsos N, Goudakos JK, Daskalakis D, Konstantinidis I, Markou K. Monoclonal antibodies for the treatment of chronic rhinosinusitis with nasal polyposis: a systematic review. Rhinology.2018;56(1):11-21.

146. Castan L, Bogh KL, Maryniak NZ, et al. Overview of in vivo and ex vivo endpoints in murine food allergy models: Suitable for evaluation of the sensitizing capacity of novel proteins? Allergy.2020;75(2):289-301.

147. Eiwegger T, Hung L, San Diego KE, O'Mahony L, Upton J. Recent developments and highlights in food allergy. Allergy.2019;74(12):2355-2367.

148. Ponce M, Diesner SC, Szepfalusi Z, Eiwegger T. Markers of tolerance development to food allergens. Allergy. 2016;71(10):1393-1404.

149. Ashley SE, Tan HT, Vuillermin P, et al. The skin barrier function gene SPINK5 is associated with challenge-proven IgE-mediated food allergy in infants. Allergy. 2017;72(9):1356-1364.

150. Tan HT, Hagner S, Ruchti F, et al. Tight junction, mucin, and inflammasome-related molecules are differentially expressed in eosinophilic, mixed, and neutrophilic experimental asthma in mice.Allergy. 2019;74(2):294-307.

151. Leung DYM, Calatroni A, Zaramela LS, et al. The nonlesional skin surface distinguishes atopic dermatitis with food allergy as a unique endotype. Sci Transl Med. 2019;11(480).

152. Goleva E, Berdyshev E, Leung DY. Epithelial barrier repair and prevention of allergy. The Journal of clinical investigation.2019;129(4):1463-1474.

153. van Ginkel CD, Flokstra-de Blok BM, Kollen BJ, Kukler J, Koppelman GH, Dubois AE. Loss-of-function variants of the filaggrin gene are associated with clinical reactivity to foods. Allergy.2015;70(4):461-464.

154. Suaini NHA, Wang Y, Soriano VX, et al. Genetic determinants of paediatric food allergy: A systematic review. Allergy.2019;74(9):1631-1648. 
155. Kivisto JE, Clarke A, Dery A, et al. Genetic and environmental susceptibility to food allergy in a registry of twins. J Allergy Clin Immunol Pract. 2019;7(8):2916-2918.

156. Marenholz I, Grosche S, Kalb B, et al. Genome-wide association study identifies the SERPINB gene cluster as a susceptibility locus for food allergy. Nat Commun. 2017;8(1):1056.

157. Do AN, Watson CT, Cohain AT, et al. Dual transcriptomic and epigenomic study of reaction severity in peanut-allergic children. The Journal of allergy and clinical immunology.2020;145(4):1219-1230.

158. Mondoulet L, Dioszeghy V, Busato F, et al. Gata3 hypermethylation and Foxp3 hypomethylation are associated with sustained protection and bystander effect following epicutaneous immunotherapy in peanutsensitized mice. Allergy. 2019;74(1):152-164.

159. D'Argenio V, Del Monaco V, Paparo L, et al. Altered miR-193a-5p expression in children with cow's milk allergy. Allergy.2018;73(2):379-386.

160. Ruffner MA, Song L, Maurer K, et al. Toll-like receptor 2 stimulation augments esophageal barrier integrity. Allergy.2019;74(12):2449-2460.

161. Rahrig S, Dettmann JM, Brauns B, et al. Transient epidermal barrier deficiency and lowered allergic threshold in filaggrin-hornerin (FlgHrnr(-/-) ) double-deficient mice. Allergy.2019;74(7):1327-1339.

162. Mitamura Y, Nunomura S, Nanri Y, et al. The IL-13/periostin/IL-24 pathway causes epidermal barrier dysfunction in allergic skin inflammation. Allergy. 2018;73(9):1881-1891.

163. Rinaldi AO, Morita H, Wawrzyniak P, et al. Direct assessment of skin epithelial barrier by electrical impedance spectroscopy. Allergy. 2019;74(10):1934-1944.

164. Chauveau A, Dalphin ML, Mauny F, et al. Skin prick tests and specific IgE in 10-year-old children: Agreement and association with allergic diseases. Allergy. 2017;72(9):1365-1373.

165. Flinterman AE, Knol EF, Lencer DA, et al. Peanut epitopes for IgE and IgG4 in peanut-sensitized children in relation to severity of peanut allergy. The Journal of allergy and clinical immunology.2008;121(3):737743 e710.

166. Caubet JC, Lin J, Ahrens B, et al. Natural tolerance development in cow's milk allergic children: $\operatorname{IgE}$ and IgG4 epitope binding. Allergy. 2017;72(11):1677-1685.

167. Cerecedo I, Zamora J, Shreffler WG, et al. Mapping of the IgE and IgG4 sequential epitopes of milk allergens with a peptide microarray-based immunoassay. The Journal of allergy and clinical immunology. 2008;122(3):589-594.

168. Sackesen C, Suarez-Farinas M, Silva R, et al. A new Luminex-based peptide assay to identify reactivity to baked, fermented, and whole milk. Allergy. 2019;74(2):327-336.

169. Suprun M, Getts R, Raghunathan R, et al. Novel Bead-Based Epitope Assay is a sensitive and reliable tool for profiling epitope-specific antibody repertoire in food allergy. Sci Rep. 2019;9(1):18425.

170. Suarez-Farinas M, Suprun M, Chang HL, et al. Predicting development of sustained unresponsiveness to milk oral immunotherapy using epitope-specific antibody binding profiles. The Journal of allergy and clinical immunology. 2019;143(3):1038-1046.

171. Monino-Romero S, Lexmond WS, Singer J, et al. Soluble FcvarepsilonRI: A biomarker for IgE-mediated diseases. Allergy.2019;74(7):1381-1384.

172. Saidova A, Hershkop AM, Ponce M, Eiwegger T. Allergen-Specific T Cells in IgE-Mediated Food Allergy. Arch Immunol Ther Exp (Warsz). 2018;66(3):161-170.

173. Chiang D, Chen X, Jones SM, et al. Single-cell profiling of peanut-responsive T cells in patients with peanut allergy reveals heterogeneous effector TH2 subsets. The Journal of allergy and clinical immunology. 
2018;141(6):2107-2120.

174. Wambre E, Bajzik V, DeLong JH, et al. A phenotypically and functionally distinct human TH2 cell subpopulation is associated with allergic disorders. Sci Transl Med. 2017;9(401).

175. Heeringa JJ, Rijvers L, Arends NJ, et al. IgE-expressing memory B cells and plasmablasts are increased in blood of children with asthma, food allergy, and atopic dermatitis. Allergy.2018;73(6):1331-1336.

176. Jimenez-Saiz R, Ellenbogen Y, Bruton K, et al. Human BCR analysis of single-sorted, putative IgE $(+)$ memory B cells in food allergy. The Journal of allergy and clinical immunology.2019;144(1):336-339 e336.

177. Nielsen SCA, Boyd SD. New technologies and applications in infant B cell immunology. Curr Opin Immunol. 2019;57:53-57.

178. Croote D, Darmanis S, Nadeau KC, Quake SR. High-affinity allergen-specific human antibodies cloned from single IgE B cell transcriptomes. Science. 2018;362(6420):1306-1309.

179. Nielsen SCA, Roskin KM, Jackson KJL, et al. Shaping of infant B cell receptor repertoires by environmental factors and infectious disease. Sci Transl Med. 2019;11(481).

180. Hoof I, Schulten V, Layhadi JA, et al. Allergen-specific $\operatorname{IgG}(+)$ memory B cells are temporally linked to IgE memory responses. The Journal of allergy and clinical immunology. 2019.

181. Heeringa JJ, McKenzie CI, Varese N, et al. Induction of IgG2 and IgG4 B-cell memory following sublingual immunotherapy for ryegrass pollen allergy. Allergy. 2019.

182. Jimenez-Saiz R, Ellenbogen Y, Koenig JFE, et al. IgG1(+) B-cell immunity predates IgE responses in epicutaneous sensitization to foods.Allergy. 2019;74(1):165-175.

183. Hoffmann HJ, Santos AF, Mayorga C, et al. The clinical utility of basophil activation testing in diagnosis and monitoring of allergic disease. Allergy. 2015;70(11):1393-1405.

184. Hemmings O, Kwok M, McKendry R, Santos AF. Basophil Activation Test: Old and New Applications in Allergy. Curr Allergy Asthma Rep. 2018;18(12):77.

185. Hung L, Obernolte H, Sewald K, Eiwegger T. Human ex vivo and in vitro disease models to study food allergy. Asia Pac Allergy.2019;9(1):e4.

186. Santos AF, Couto-Francisco N, Becares N, Kwok M, Bahnson HT, Lack G. A novel human mast cell activation test for peanut allergy. The Journal of allergy and clinical immunology. 2018;142(2):689-691 e689.

187. Bahri R, Custovic A, Korosec P, et al. Mast cell activation test in the diagnosis of allergic disease and anaphylaxis. The Journal of allergy and clinical immunology. 2018;142(2):485-496 e416.

188. Pouessel G, Beaudouin E, Tanno LK, et al. Food-related anaphylaxis fatalities: Analysis of the Allergy Vigilance Network((R)) database.Allergy. 2019;74(6):1193-1196.

189. Pouessel G, Turner PJ, Worm M, et al. Food-induced fatal anaphylaxis: From epidemiological data to general prevention strategies. Clin Exp Allergy. 2018;48(12):1584-1593.

190. De Schryver S, Halbrich M, Clarke A, et al. Tryptase levels in children presenting with anaphylaxis: Temporal trends and associated factors. The Journal of allergy and clinical immunology.2016;137(4):11381142 .

191. Mayorga C, Fernandez TD, Montanez MI, Moreno E, Torres MJ. Recent developments and highlights in drug hypersensitivity. Allergy.2019;74(12):2368-2381.

192. Romano A, Atanaskovic-Markovic M, Barbaud A, et al. Towards a more precise diagnosis of hypersensitivity to beta-lactams - an EAACI position paper. Allergy. 2019. 
193. Brockow K, Garvey LH, Aberer W, et al. Skin test concentrations for systemically administered drugs - an ENDA/EAACI Drug Allergy Interest Group position paper. Allergy. 2013;68(6):702-712.

194. Torres MJ, Celik GE, Whitaker P, et al. A EAACI drug allergy interest group survey on how European allergy specialists deal with $\beta$-lactam allergy. Allergy. 2019;74(6):1052-1062.

195. Dona I, Romano A, Torres MJ. Algorithm for betalactam allergy diagnosis. Allergy. 2019;74(9):18171819.

196. Barbero N, Fernandez-Santamaria R, Mayorga C, et al. Identification of an antigenic determinant of clavulanic acid responsible for IgE-mediated reactions. Allergy. 2019;74(8):1490-1501.

197. Torres MJ, Celik GE, Whitaker P, et al. A EAACI drug allergy interest group survey on how European allergy specialists deal with beta-lactam allergy. Allergy. 2019;74(6):1052-1062.

198. Yang MS, Kang DY, Seo B, et al. Incidence of cephalosporin-induced anaphylaxis and clinical efficacy of screening intradermal tests with cephalosporins: A large multicenter retrospective cohort study.Allergy. 2018;73(9):1833-1841.

199. Dona I, Perez-Sanchez N, Salas M, et al. Clinical Characterization and Diagnostic Approaches for Patients Reporting Hypersensitivity Reactions to Quinolones. The journal of allergy and clinical immunology In practice. 2020.

200. Porebski G, Pecaric-Petkovic T, Groux-Keller M, Bosak M, Kawabata TT, Pichler WJ. In vitro drug causality assessment in Stevens-Johnson syndrome - alternatives for lymphocyte transformation test. Clin Exp Allergy. 2013;43(9):1027-1037.

201. Mayorga C, Celik G, Rouzaire P, et al. In vitro tests for drug hypersensitivity reactions: an ENDA/EAACI Drug Allergy Interest Group position paper. Allergy. 2016;71(8):1103-1134.

202. Fontaine C, Mayorga C, Bousquet PJ, et al. Relevance of the determination of serum-specific IgE antibodies in the diagnosis of immediate beta-lactam allergy. Allergy. 2007;62(1):47-52.

203. Johansson SG, Adedoyin J, van Hage M, Gronneberg R, Nopp A. False-positive penicillin immunoassay: an unnoticed common problem. The Journal of allergy and clinical immunology.2013;132(1):235-237.

204. Torres MJ, Padial A, Mayorga C, et al. The diagnostic interpretation of basophil activation test in immediate allergic reactions to betalactams. Clin Exp Allergy.2004;34(11):1768-1775.

205. Torres MJ, Ariza A, Mayorga C, et al. Clavulanic acid can be the component in amoxicillin-clavulanic acid responsible for immediate hypersensitivity reactions. The Journal of allergy and clinical immunology. 2010;125(2):502-505 e502.

206. Fernandez TD, Ariza A, Palomares F, et al. Hypersensitivity to fluoroquinolones: The expression of basophil activation markers depends on the clinical entity and the culprit fluoroquinolone. Medicine (Baltimore). 2016;95(23):e3679.

207. Fernandez TD, Torres MJ, Blanca-Lopez N, et al. Negativization rates of IgE radioimmunoassay and basophil activation test in immediate reactions to penicillins. Allergy. 2009;64(2):242-248.

208. Van Gasse AL, Sabato V, Uyttebroek AP, et al. Immediate moxifloxacin hypersensitivity: Is there more than currently meets the eye? Allergy. 2017;72(12):2039-2043.

209. Fernandez-Santamaria R, Palomares F, Salas M, et al. Expression of the Tim3-galectin-9 axis is altered in drug-induced maculopapular exanthema. Allergy. 2019;74(9):1769-1779.

210. Dona I, Perez-Sanchez N, Eguiluz-Gracia I, et al. Progress in understanding hypersensitivity reactions to nonsteroidal anti-inflammatory drugs. Allergy. 2020;75(3):561-575. 
211. Dona I, Perez-Sanchez N, Bogas G, Moreno E, Salas M, Torres MJ. Medical algorithm: Diagnosis and treatment of NSAIDs hypersensitivity.Allergy. 2019.

212. Dona I, Barrionuevo E, Salas M, et al. NSAIDs-hypersensitivity often induces a blended reaction pattern involving multiple organs.Sci Rep. 2018;8(1):16710.

213. Blanca M, Oussalah A, Cornejo-Garcia JA, et al. GNAI2 variants predict nonsteroidal antiinflammatory drug hypersensitivity in a genome-wide study. Allergy. 2020;75(5):1250-1253.

214. Lee HY, Ye YM, Kim SH, et al. Identification of phenotypic clusters of nonsteroidal anti-inflammatory drugs exacerbated respiratory disease.Allergy. 2017;72(4):616-626.

215. Dona I, Jurado-Escobar R, Perkins JR, et al. Eicosanoid mediator profiles in different phenotypes of nonsteroidal anti-inflammatory drug-induced urticaria. Allergy. 2019;74(6):1135-1144.

216. Hagan JB, Laidlaw TM, Divekar R, et al. Urinary Leukotriene E4 to Determine Aspirin Intolerance in Asthma: A Systematic Review and Meta-Analysis. J Allergy Clin Immunol Pract. 2017;5(4):990-997 e991.

217. Ban GY, Cho K, Kim SH, et al. Metabolomic analysis identifies potential diagnostic biomarkers for aspirin-exacerbated respiratory disease. Clin Exp Allergy. 2017;47(1):37-47.

218. Lei DK, Saltoun C. Allergen immunotherapy: definition, indications, and reactions. Allergy Asthma Proc. 2019;40(6):369-371.

219. Miller JM, Davis CM, Anvari S. The clinical and immune outcomes after food allergen immunotherapy emphasizing the development of tolerance. Curr Opin Pediatr. 2019;31(6):821-827.

220. Sindher SB, Long A, Acharya S, Sampath V, Nadeau KC. The Use of Biomarkers to Predict AeroAllergen and Food Immunotherapy Responses. Clin Rev Allergy Immunol. 2018;55(2):190-204.

221. Couroux P, Ipsen H, Stage BS, et al. A birch sublingual allergy immunotherapy tablet reduces rhinoconjunctivitis symptoms when exposed to birch and oak and induces IgG4 to allergens from all trees in the birch homologous group. Allergy. 2019;74(2):361-369.

222. Huang Y, Wang C, Wang X, Zhang L, Lou H. Efficacy and safety of subcutaneous immunotherapy with house dust mite for allergic rhinitis: A Meta-analysis of Randomized Controlled Trials. Allergy.2019;74(1):189-192.

223. Schmitt J, Wustenberg E, Kuster D, Mucke V, Serup-Hansen N, Tesch F. The moderating role of allergy immunotherapy in asthma progression: Results of a population-based cohort study. Allergy.2020;75(3):596602.

224. Varona R, Ramos T, Escribese MM, et al. Persistent regulatory T-cell response 2 years after 3 years of grass tablet SLIT: Links to reduced eosinophil counts, sIgE levels, and clinical benefit.Allergy. 2019;74(2):349-360.

225. Wahn U, Bachert C, Heinrich J, Richter H, Zielen S. Real-world benefits of allergen immunotherapy for birch pollen-associated allergic rhinitis and asthma. Allergy. 2019;74(3):594-604.

226. Investigators PGoC, Vickery BP, Vereda A, et al. AR101 Oral Immunotherapy for Peanut Allergy. The New England journal of medicine. 2018;379(21):1991-2001.

227. Virkud YV, Kelly RS, Wood C, Lasky-Su JA. The nuts and bolts of omics for the clinical allergist. Ann Allergy Asthma Immunol.2019;123(6):558-563.

228. van Zelm MC, McKenzie CI, Varese N, Rolland JM, O'Hehir RE. Recent developments and highlights in immune monitoring of allergen immunotherapy. Allergy. 2019;74(12):2342-2354. 
229. Kim EH, Yang L, Ye P, et al. Long-term sublingual immunotherapy for peanut allergy in children: Clinical and immunologic evidence of desensitization. The Journal of allergy and clinical immunology.2019;144(5):1320-1326 e1321.

230. Shamji MH, Kappen JH, Akdis M, et al. Biomarkers for monitoring clinical efficacy of allergen immunotherapy for allergic rhinoconjunctivitis and allergic asthma: an EAACI Position Paper.Allergy. 2017;72(8):1156-1173.

231. Viswanathan RK, Busse WW. Allergen immunotherapy in allergic respiratory diseases: from mechanisms to meta-analyses. Chest.2012;141(5):1303-1314.

232. Datema MR, Eller E, Zwinderman AH, et al. Ratios of specific IgG4 over IgE antibodies do not improve prediction of peanut allergy nor of its severity compared to specific IgE alone. Clin Exp Allergy.2019;49(2):216-226.

233. Kulis M, Yue X, Guo R, et al. High- and low-dose oral immunotherapy similarly suppress pro-allergic cytokines and basophil activation in young children. Clin Exp Allergy. 2019;49(2):180-189.

234. Chinthrajah RS, Purington N, Andorf S, et al. Sustained outcomes in oral immunotherapy for peanut allergy (POISED study): a large, randomised, double-blind, placebo-controlled, phase 2 study.Lancet. 2019;394(10207):1437-1449.

235. Feng M, Su Q, Lai X, et al. Functional and Immunoreactive Levels of IgG4 Correlate with Clinical Responses during the Maintenance Phase of House Dust Mite Immunotherapy. J Immunol. 2018;200(12):38973904 .

236. Fukano C, Ohashi-Doi K, Lund K, Nakao A, Masuyama K, Matsuoka T. Establishment of enzymelinked immunosorbent facilitated antigen binding as a biomarker assay for Japanese cedar pollen allergy immunotherapy.J Pharmacol Sci. 2019;140(3):223-227.

237. Chinthrajah RS, Purington N, Sampath V, et al. High dimensional immune biomarkers demonstrate differences in phenotypes and endotypes in food allergy and asthma. Ann Allergy Asthma Immunol.2018;121(1):117-119 e111.

238. Boonpiyathad T, Meyer N, Moniuszko M, et al. High-dose bee venom exposure induces similar tolerogenic B-cell responses in allergic patients and healthy beekeepers. Allergy. 2017;72(3):407-415.

239. Cianferoni A, Saltzman R, Saretta F, et al. Invariant natural killer cells change after an oral allergy desensitization protocol for cow's milk. Clin Exp Allergy. 2017;47(11):1390-1397.

240. Schulten V, Tripple V, Seumois G, et al. Allergen-specific immunotherapy modulates the balance of circulating Tfh and Tfr cells. The Journal of allergy and clinical immunology.2018;141(2):775-777.e776.

241. Yao Y, Wang ZC, Wang N, et al. Allergen immunotherapy improves defective follicular regulatory $\mathrm{T}$ cells in patients with allergic rhinitis. The Journal of allergy and clinical immunology.2019;144(1):118-128.

242. Boonpiyathad T, Sokolowska M, Morita H, et al. Der p 1-specific regulatory T-cell response during house dust mite allergen immunotherapy. Allergy. 2019;74(5):976-985.

243. Boonpiyathad T, van de Veen W, Wirz O, et al. Role of Der p 1-specific B cells in immune tolerance during 2 years of house dust mite-specific immunotherapy. The Journal of allergy and clinical immunology. 2019;143(3):1077-1086 e1010.

244. Sharif H, Singh I, Kouser L, et al. Immunologic mechanisms of a short-course of Lolium perenne peptide immunotherapy: A randomized, double-blind, placebo-controlled trial. The Journal of allergy and clinical immunology. 2019;144(3):738-749.

245. Sage PT, Alvarez D, Godec J, von Andrian UH, Sharpe AH. Circulating T follicular regulatory and helper cells have memory-like properties. The Journal of clinical investigation. 2014;124(12):5191-5204. 
246. Sun L, Jin H, Li H. GARP: a surface molecule of regulatory T cells that is involved in the regulatory function and TGF- $\beta$ releasing. Oncotarget. 2016;7(27):42826-42836.

247. Caruso M, Cibella F, Emma R, et al. Basophil biomarkers as useful predictors for sublingual immunotherapy in allergic rhinitis. Int Immunopharmacol. 2018;60:50-58.

248. Van Overtvelt L, Baron-Bodo V, Horiot S, et al. Changes in basophil activation during grass-pollen sublingual immunotherapy do not correlate with clinical efficacy. Allergy. 2011;66(12):1530-1537.

249. Ihara F, Sakurai D, Yonekura S, et al. Identification of specifically reduced Th2 cell subsets in allergic rhinitis patients after sublingual immunotherapy. Allergy. 2018;73(9):1823-1832.

250. Gueguen C, Luce S, Lombardi V, Baron-Bodo V, Moingeon P, Mascarell L. IL-10 mRNA levels in whole blood cells correlate with house dust mite allergen immunotherapy efficacy. Allergy. 2019;74(11):2223-2226.

251. Potaczek DP, Harb H, Michel S, Alhamwe BA, Renz H, Tost J. Epigenetics and allergy: from basic mechanisms to clinical applications. Epigenomics. 2017;9(4):539-571.

252. Zhang H, Kaushal A, Merid SK, et al. DNA methylation and allergic sensitizations: A genome-scale longitudinal study during adolescence.Allergy. 2019;74(6):1166-1175.

253. Syed A, Garcia MA, Lyu SC, et al. Peanut oral immunotherapy results in increased antigen-induced regulatory T-cell function and hypomethylation of forkhead box protein 3 (FOXP3). The Journal of allergy and clinical immunology. 2014;133(2):500-510.

254. Tsai M, Mukai K, Chinthrajah RS, Nadeau KC, Galli SJ. Sustained successful peanut oral immunotherapy associated with low basophil activation and peanut-specific IgE. The Journal of allergy and clinical immunology. 2020;145(3):885-896 e886.

255. Burton OT, Logsdon SL, Zhou JS, et al. Oral immunotherapy induces IgG antibodies that act through FcgammaRIIb to suppress IgE-mediated hypersensitivity. The Journal of allergy and clinical immunology.2014;134(6):1310-1317 e1316.

256. Frischmeyer-Guerrerio PA, Masilamani M, Gu W, et al. Mechanistic correlates of clinical responses to omalizumab in the setting of oral immunotherapy for milk allergy. The Journal of allergy and clinical immunology. 2017;140(4):1043-1053 e1048.

257. Vickery BP, Berglund JP, Burk CM, et al. Early oral immunotherapy in peanut-allergic preschool children is safe and highly effective. The Journal of allergy and clinical immunology.2017;139(1):173-181 e178.

258. Ryan JF, Hovde R, Glanville J, et al. Successful immunotherapy induces previously unidentified allergen-specific CD4+ T-cell subsets.Proceedings of the National Academy of Sciences of the United States of America. 2016;113(9):E1286-1295.

259. Bedoret D, Singh AK, Shaw V, et al. Changes in antigen-specific T-cell number and function during oral desensitization in cow's milk allergy enabled with omalizumab. Mucosal Immunol.2012;5(3):267-276.

260. Abdel-Gadir A, Schneider L, Casini A, et al. Oral immunotherapy with omalizumab reverses the Th2 cell-like programme of regulatory T cells and restores their function. Clin Exp Allergy.2018;48(7):825-836.

261. Blumchen K, Trendelenburg V, Ahrens F, et al. Efficacy, Safety, and Quality of Life in a Multicenter, Randomized, Placebo-Controlled Trial of Low-Dose Peanut Oral Immunotherapy in Children with Peanut Allergy.J Allergy Clin Immunol Pract. 2019;7(2):479-491 e410.

262. Syed IA, Sulaiman SA, Hassali MA, Syed SH, Shan LH, Lee CK. Factors associated with poor CD4 and viral load outcomes in patients with HIV/AIDS. J Med Virol. 2016;88(5):790-797.

263. Berin MC, Grishin A, Masilamani M, et al. Egg-specific IgE and basophil activation but not eggspecific T-cell counts correlate with phenotypes of clinical egg allergy. The Journal of allergy and clinical immunology. 2018;142(1):149-158 e148. 
264. Gorelik M, Narisety SD, Guerrerio AL, et al. Suppression of the immunologic response to peanut during immunotherapy is often transient. The Journal of allergy and clinical immunology.2015;135(5):1283-1292.

265. Flores Kim J, McCleary N, Nwaru BI, Stoddart A, Sheikh A. Diagnostic accuracy, risk assessment, and cost-effectiveness of component-resolved diagnostics for food allergy: A systematic review. Allergy. 2018;73(8):1609-1621.

266. Eller E, Bindslev-Jensen C. Clinical value of component-resolved diagnostics in peanut-allergic patients. Allergy.2013;68(2):190-194.

267. Klemans RJ, Otte D, Knol M, et al. The diagnostic value of specific IgE to Ara h 2 to predict peanut allergy in children is comparable to a validated and updated diagnostic prediction model. The Journal of allergy and clinical immunology. 2013;131(1):157-163.

268. Kukkonen AK, Pelkonen AS, Makinen-Kiljunen S, Voutilainen H, Makela MJ. Ara h 2 and Ara 6 are the best predictors of severe peanut allergy: a double-blind placebo-controlled study. Allergy.2015;70(10):12391245 .

269. Martinet J, Couderc L, Renosi F, Bobée V, Marguet C, Boyer O. Diagnostic Value of Antigen-Specific Immunoglobulin E Immunoassays against Ara h 2 and Ara h 8 Peanut Components in Child Food Allergy.International archives of allergy and immunology.2016;169(4):216-222.

270. Holzhauser T, Wackermann O, Ballmer-Weber BK, et al. Soybean (Glycine max) allergy in Europe: Gly m 5 (beta-conglycinin) and Gly $\mathrm{m} 6$ (glycinin) are potential diagnostic markers for severe allergic reactions to soy. The Journal of allergy and clinical immunology.2009;123(2):452-458.

271. Ebisawa M, Brostedt P, Sjolander S, Sato S, Borres MP, Ito K. Gly m 2 S albumin is a major allergen with a high diagnostic value in soybean-allergic children. The Journal of allergy and clinical immunology. 2013;132(4):976-978 e971-975.

272. Klemans RJ, Knol EF, Michelsen-Huisman A, et al. Components in soy allergy diagnostics: Gly m $2 \mathrm{~S}$ albumin has the best diagnostic value in adults. Allergy. 2013;68(11):1396-1402.

273. Masthoff LJ, Mattsson L, Zuidmeer-Jongejan L, et al. Sensitization to Cor a 9 and Cor a 14 is highly specific for a hazelnut allergy with objective symptoms in Dutch children and adults. The Journal of allergy and clinical immunology. 2013;132(2):393-399.

274. Faber MA, De Graag M, Van Der Heijden C, et al. Cor a 14: missing link in the molecular diagnosis of hazelnut allergy? International archives of allergy and immunology. 2014;164(3):200-206.

275. Datema MR, van Ree R, Asero R, et al. Component-resolved diagnosis and beyond: Multivariable regression models to predict severity of hazelnut allergy. Allergy. 2018;73(3):549-559.

276. Beyer K, Grabenhenrich L, Hartl M, et al. Predictive values of component-specific IgE for the outcome of peanut and hazelnut food challenges in children. Allergy. 2015;70(1):90-98.

277. Ciprandi G, Pistorio A, Silvestri M, Rossi GA, Tosca MA. Walnut anaphylaxis: the usefulness of molecular-based allergy diagnostics.Immunol Lett. 2014;161(1):138-139.

278. Ballmer-Weber BK, Lidholm J, Lange L, et al. Allergen Recognition Patterns in Walnut Allergy Are Age Dependent and Correlate with the Severity of Allergic Reactions. J Allergy Clin Immunol Pract.2019;7(5):1560-1567 e1566.

279. Lee J, Jeong K, Jeon SA, Lee S. Component resolved diagnosis of walnut allergy in young children: Jug r 1 as a major walnut allergen.Asian Pac J Allergy Immunol. 2019.

280. Giovannini M, Comberiati P, Piazza M, et al. Retrospective definition of reaction risk in Italian children with peanut, hazelnut and walnut allergy through component-resolved diagnosis. Allergol Immunopathol (Madr). 2019;47(1):73-78. 
281. Savvatianos S, Konstantinopoulos AP, Borga A, et al. Sensitization to cashew nut $2 \mathrm{~S}$ albumin, Ana o 3 , is highly predictive of cashew and pistachio allergy in Greek children. The Journal of allergy and clinical immunology. 2015;136(1):192-194.

282. van der Valk JP, Gerth van Wijk R, Vergouwe Y, et al. sIgE Ana o 1, 2 and 3 accurately distinguish tolerant from allergic children sensitized to cashew nuts. Clin Exp Allergy. 2017;47(1):113-120.

283. Lange L, Lasota L, Finger A, et al. Ana o 3-specific IgE is a good predictor for clinically relevant cashew allergy in children.Allergy. 2017;72(4):598-603.

284. Dang TD, Peters RL, Koplin JJ, et al. Egg allergen specific IgE diversity predicts resolution of egg allergy in the population cohort HealthNuts. Allergy. 2019;74(2):318-326.

285. Pascal M, Grishina G, Yang AC, et al. Molecular Diagnosis of Shrimp Allergy: Efficiency of Several Allergens to Predict Clinical Reactivity.J Allergy Clin Immunol Pract. 2015;3(4):521-529 e510.

286. Gao Z, Fu WY, Sun Y, et al. Artemisia pollen allergy in China: Component-resolved diagnosis reveals allergic asthma patients have significant multiple allergen sensitization. Allergy.2019;74(2):284-293.

287. Uriarte SA, Sastre J. Clinical relevance of molecular diagnosis in pet allergy. Allergy. 2016;71(7):10661068 .

288. Posa D, Perna S, Resch Y, et al. Evolution and predictive value of IgE responses toward a comprehensive panel of house dust mite allergens during the first 2 decades of life. The Journal of allergy and clinical immunology. 2017;139(2):541-549 e548.

289. Simon D, Page B, Vogel M, et al. Evidence of an abnormal epithelial barrier in active, untreated and corticosteroid-treated eosinophilic esophagitis. Allergy. 2018;73(1):239-247.

290. Akdis CA, Arkwright PD, Bruggen MC, et al. Type 2 immunity in the skin and lungs. Allergy. 2020.

291. Kubo T, Wawrzyniak P, Morita H, et al. CpG-DNA enhances the tight junction integrity of the bronchial epithelial cell barrier. J Allergy Clin Immunol. 2015;136(5):1413-1416 e1411-1418.

292. Soyka MB, Wawrzyniak P, Eiwegger T, et al. Defective epithelial barrier in chronic rhinosinusitis: the regulation of tight junctions by IFN-gamma and IL-4. J Allergy Clin Immunol. 2012;130(5):1087-1096 e1010.

293. Wawrzyniak P, Wawrzyniak M, Wanke K, et al. Regulation of bronchial epithelial barrier integrity by type 2 cytokines and histone deacetylases in asthmatic patients. J Allergy Clin Immunol.2017;139(1):93-103.

294. Kortekaas Krohn I, Seys SF, Lund G, et al. Nasal epithelial barrier dysfunction increases sensitization and mast cell degranulation in the absence of allergic inflammation. Allergy. 2020;75(5):1155-1164.

295. Werfel T, Allam JP, Biedermann T, et al. Cellular and molecular immunologic mechanisms in patients with atopic dermatitis. J Allergy Clin Immunol. 2016;138(2):336-349.

296. McAleer MA, Irvine AD. The multifunctional role of filaggrin in allergic skin disease. J Allergy Clin Immunol.2013;131(2):280-291.

297. Jin Y, Lu L, Tu W, Luo T, Fu Z. Impacts of polystyrene microplastic on the gut barrier, microbiota and metabolism of mice. Sci Total Environ. 2019;649:308-317.

298. Hole AM, Draper A, Jolliffe G, Cullinan P, Jones M, Taylor AJ. Occupational asthma caused by bacillary amylase used in the detergent industry. Occup Environ Med. 2000;57(12):840-842.

299. Sugita K, Altunbulakli C, Morita H, et al. Human type 2 innate lymphoid cells disrupt skin keratinocyte tight junction barrier by IL-13. Allergy. 2019;74(12):2534-2537.

300. Zhou X, Wei T, Cox CW, Jiang Y, Roche WR, Walls AF. Mast cell chymase impairs bronchial epithelium integrity by degrading cell junction molecules of epithelial cells. Allergy.2019;74(7):1266-1276. 
301. Steelant B, Wawrzyniak P, Martens K, et al. Blocking histone deacetylase activity as a novel target for epithelial barrier defects in patients with allergic rhinitis. J Allergy Clin Immunol.2019;144(5):1242-1253 e1247.

302. Kelleher MM, Dunn-Galvin A, Gray C, et al. Skin barrier impairment at birth predicts food allergy at 2 years of age. J Allergy Clin Immunol. 2016;137(4):1111-1116 e1111-1118.

303. Sindher S, Alkotob SS, Shojinaga MN, et al. Pilot study measuring transepidermal water loss (TEWL) in children suggests trilipid cream is more effective than a paraffin-based emollient. Allergy. 2020.

304. Antonov D, Schliemann S, Elsner P. Methods for the Assessment of Barrier Function. Curr Probl Dermatol. 2016;49:61-70.

305. Birgersson U, Birgersson E, Aberg P, Nicander I, Ollmar S. Non-invasive bioimpedance of intact skin: mathematical modeling and experiments. Physiol Meas. 2011;32(1):1-18.

306. Fasano A, Shea-Donohue T. Mechanisms of disease: the role of intestinal barrier function in the pathogenesis of gastrointestinal autoimmune diseases. Nat Clin Pract Gastroenterol Hepatol.2005;2(9):416-422.

307. Mu Q, Kirby J, Reilly CM, Luo XM. Leaky Gut As a Danger Signal for Autoimmune Diseases. Front Immunol. 2017;8:598.

308. Jiminez JA, Uwiera TC, Douglas Inglis G, Uwiera RR. Animal models to study acute and chronic intestinal inflammation in mammals. Gut Pathog. 2015;7:29.

309. Camara-Lemarroy CR, Silva C, Greenfield J, Liu WQ, Metz LM, Yong VW. Biomarkers of intestinal barrier function in multiple sclerosis are associated with disease activity. Mult Scler.2019:1352458519863133.

310. Bosi E, Molteni L, Radaelli MG, et al. Increased intestinal permeability precedes clinical onset of type 1 diabetes.Diabetologia. 2006;49(12):2824-2827.

311. Fasano A. Zonulin, regulation of tight junctions, and autoimmune diseases. Ann $N$ Y Acad Sci. 2012;1258:25-33.

312. Kiecolt-Glaser JK, Wilson SJ, Bailey ML, et al. Marital distress, depression, and a leaky gut: Translocation of bacterial endotoxin as a pathway to inflammation. Psychoneuroendocrinology. 2018;98:52-60.

313. Alinaghi M, Nguyen DN, Sangild PT, Bertram HC. Direct Implementation of Intestinal Permeability Test in NMR Metabolomics for Simultaneous Biomarker Discovery-A Feasibility Study in a Preterm Piglet Model. Metabolites. 2020;10(1).

314. Muraro A, Roberts G, Halken S, et al. EAACI guidelines on allergen immunotherapy: Executive statement. Allergy. 2018;73(4):739-743.

315. European Medicines Agency. Commitee for medicinal products for human use (CHMP): Guideline on the Clinical Development of Products for Specific Immunotherapy for The Treatment of Allergic Diseases (CHMP/EWP/18504/2006). Available from: http://www.ema.europa.eu/docs/en_GB/document_library/Scientific_guideline/2009/09/WC500003605.pdf; 2008. 2008.

316. Bonertz A, Roberts G, Slater JE, et al. Allergen manufacturing and quality aspects for allergen immunotherapy in Europe and the United States: An analysis from the EAACI AIT Guidelines Project.Allergy. 2018;73(4):816-826.

317. Kaul S, Englert L, May S, Vieths S. Regulatory aspects of specific immunotherapy in Europe. Curr Opin Allergy Clin Immunol.2010;10(6):594-602.

318. Englert L, May S, Kaul S, Vieths S. [The therapy allergens ordinance ("Therapieallergene-Verordnung"). Background and effects].Bundesgesundheitsblatt Gesundheitsforschung Gesundheitsschutz.2012;55(3):351357. 
319. Mahler V, Esch RE, Kleine-Tebbe J, et al. Understanding differences in allergen immunotherapy products and practices in North America and Europe. The Journal of allergy and clinical immunology.2019;143(3):813-828.

320. Pfaar O, Agache I, de Blay F, et al. Perspectives in allergen immunotherapy: 2019 and beyond. Allergy. 2019;74 Suppl 108:3-25.

321. Dhami S, Nurmatov U, Arasi S, et al. Allergen immunotherapy for allergic rhinoconjunctivitis: A systematic review and meta-analysis.Allergy. 2017;72(11):1597-1631.

322. German Society for Allergology and Clinical Immunology (DGAKI). http://www.dgaki.de/leitlinien/s2k-leitlinie-sit/ (accessed on 07 Dec 2018).

323. Roberts G, Pfaar O, Akdis CA, et al. EAACI Guidelines on Allergen Immunotherapy: Allergic rhinoconjunctivitis. Allergy.2018;73(4):765-798.

324. Pfaar O, Alvaro M, Cardona V, Hamelmann E, Mosges R, Kleine-Tebbe J. Clinical trials in allergen immunotherapy: current concepts and future needs. Allergy. 2018;73(9):1775-1783.

325. https://www.clinicaltrialsregister.eu/ctr-search/search?query=2016-000051-27.

326. Auge J, Vent J, Agache I, et al. EAACI Position paper on the standardization of nasal allergen challenges. Allergy.2018;73(8):1597-1608.

327. Fauquert JL, Jedrzejczak-Czechowicz M, Rondon C, et al. Conjunctival allergen provocation test : guidelines for daily practice.Allergy. 2017;72(1):43-54.

328. Pfaar O, Demoly P, Gerth van Wijk R, et al. Recommendations for the standardization of clinical outcomes used in allergen immunotherapy trials for allergic rhinoconjunctivitis: an EAACI Position Paper.Allergy. 2014;69(7):854-867.

329. Mosges R, Bachert C, Panzner P, et al. Short course of grass allergen peptides immunotherapy over 3 weeks reduces seasonal symptoms in allergic rhinoconjunctivitis with/without asthma: A randomized, multicenter, double-blind, placebo-controlled trial. Allergy.2018;73(9):1842-1850.

330. Vély F, Barlogis V, Vallentin B, et al. Evidence of innate lymphoid cell redundancy in humans. Nat Immunol. 2016;17(11):1291.

331. Pfaar O, Bachert C, Kuna P, et al. Sublingual allergen immunotherapy with a liquid birch pollen product in patients with seasonal allergic rhinoconjunctivitis with or without asthma. The Journal of allergy and clinical immunology. 2019;143(3):970-977.

332. Pfaar O, Gerth van Wijk R, Klimek L, Bousquet J, Creticos P. Clinical trials in allergen immunotherapy in the age group of children and adolescents: current concepts and future needs. Clinical and Translational Allergy. 2020;10:1-8.

333. Pfaar O, Bastl K, Berger U, et al. Defining pollen exposure times for clinical trials of allergen immunotherapy for pollen-induced rhinoconjunctivitis - an EAACI position paper. Allergy.2017;72(5):713-722.

334. Karatzas K, Riga M, Berger U, Werchan M, Pfaar O, Bergmann KC. Computational validation of the recently proposed pollen season definition criteria. Allergy. 2018;73(1):5-7.

335. Pfaar O, Karatzas K, Bastl K, et al. Pollen season is reflected on symptom load for grass and birch pollen-induced allergic rhinitis in different geographic areas-An EAACI Task Force Report. Allergy.2019.

336. Pfaar O, Agache I, Bergmann K, et al. Placebo effects in allergen immunotherapy-an EAACI Task Force Position Paper. Allergy. 2020.

337. Pfaar O, Bonini S, Cardona V, et al. Perspectives in allergen immunotherapy: 2017 and beyond. Allergy. 2018;73 Suppl 104:5-23. 
338. Guyatt GH, Oxman AD, Vist GE, et al. GRADE: an emerging consensus on rating quality of evidence and strength of recommendations.Bmj. 2008;336(7650):924-926.

339. Guyatt G, Oxman AD, Akl EA, et al. GRADE guidelines: 1. Introduction-GRADE evidence profiles and summary of findings tables. Journal of clinical epidemiology. 2011;64(4):383-394.

340. Santesso N, Glenton C, Dahm P, et al. GRADE guidelines 26: Informative statements to communicate the findings of systematic reviews of interventions. Journal of clinical epidemiology.2020;119:126-135.

341. Agache I, Beltran J, Akdis C, et al. Efficacy and safety of treatment with biologicals (benralizumab, dupilumab, mepolizumab, omalizumab and reslizumab) for severe eosinophilic asthma. A systematic review for the EAACI Guidelines-recommendations on the use of biologicals in severe asthma. Allergy. 2020;75(5):10231042 .

342. Agache I, Rocha C, Beltran J, et al. Efficacy and safety of treatment with biologicals (benralizumab, dupilumab and omalizumab) for severe allergic asthma: A systematic review for the EAACI Guidelines recommendations on the use of biologicals in severe asthma.Allergy. 2020;75(5):1043-1057.

343. Agache I, Song Y, Rocha C, et al. Efficacy and safety of treatment with dupilumab for severe asthma: A systematic review of the EAACI guidelines-Recommendations on the use of biologicals in severe asthma.Allergy. 2020;75(5):1058-1068.

344. Agache I, Lau S, Akdis CA, et al. EAACI Guidelines on Allergen Immunotherapy: House dust mitedriven allergic asthma. Allergy.2019;74(5):855-873.

\section{Figure Legends}

Figure 1: Treatment based on molecular biomarkers for endotypes in asthma. Asthma can be subdivided into type 2 (high) and non-type 2 (or type 2 low) endotypes based on their underlying inflammatory pathways. For type 2 high asthma, potential biomarkers could be serum specific IgE (sIgE), fractional exhaled nitric oxide (FeNO) and blood or sputum eosinophils, and in some more specialized centres periostin. Moreover, type 2 cytokines (IL-4, IL-5 and IL-13) and innate (epithelial) cytokines (IL-25, IL-33 and TSLP) can also be important biomarkers. The options to treat with biologicals emphasizing biomarkers of Type 2 high endotype have entered the market: $\operatorname{IgE}$ (Omalizumab), IL-5 (Mepolizumab, Reslizumab, Benralizumab) and IL-4/IL-13 (Dupilumab). In contrast, the diagnosis of type 2 low asthma is difficult to establish as generally based on increased sputum neutrophils or pauci-granulocytic with normal levels of other type 2 markers, and non-type 2 cytokines (IL-8 or IL-17). There are still some associated indicators including obesity, smoking habits and psychological aspects. Therefore, therapeutic strategies for patients with type 2 low asthma could be macrolides and bronchial thermoplasty.

Figure 2: Microbiome Biomarkers in Asthma. Alterations in the gut and airway microbiota during childhood have been associated with asthma risk. The higher relative abundance of Veillonella and Prevotella and a switch from aCorynebacterium and Dolosigranulum cluster to aMoraxella cluster in the upperairways were associated with a higher risk of severe asthma exacerbation in children with asthma. The lower relative abundance of genera including Lachnospira, Veillonella, Faecalibacterium, Rothia ,Bifidobacterium and Akkermansia in the gut during early life have been associated with the development of asthma. The increases in relative abundance of Gemmiger, Escherichia, Candidaand Rhodotorula within the gut were also associated with the subsequent development of asthma.

Figure 3: Immune cells and mediators as biomarkers in allergic rhinitis (AR). AR is associated with abnormalities in epithelial barrier function which is caused by exposure to exogenous proteases from allergens bacteria and viruses. These changes in epithelial barrier could contribute to the allergen absorption and disruption of epithelial tight junction. Activated dendritic cells (DCs) present allergen peptides to naive T cells and drive them to differentiate into Th2 cells and also allergen specific Th2A cells. Damaged epithelial cells release a high level of alarmin (TSLP, IL-25, and IL-33), which activate the group 2 innate lymphoid cells (ILC2s) as well as pathogenic memory T helper (Th) 2 cells. All these cells produce large amounts of 
proinflammatory mediators including IL-4, IL-5, IL-9, and IL-13. Besides, IL-4 and IL-13 are involved in IgE class-switch in B cells. IgE binding to mast cells can trigger the release of mast cell-associated mediators, such as prostaglandin D2 and leukotrienes, which could also activate the function of ILC2. PGD2 signaling could be a promising biomarker, as it can also activate eosinophils and basophils. Moreover, CD203c expression on basophils exhibits a time-of-day-dependent variation, which could partly be responsible for temporal symptomatic variations in AR. IgG4 increased during allergen immunotherapy (AIT) is purported to be a blocking antibody by competing for allergen binding with IgE bound to Fce receptors on mast cells and basophils.cysLT, Leukotrienes; PGD2, prostaglandin D2.

Figure 4: Biomarkers of viral infections in the exacerbation of AR. After the epithelial cells are infected with viruses, the replicating virus can cause cell lysis and direct damage to the epithelium which causes deficiency in the production of antiviral interferon (IFN)- $\beta$ and IFN- $\lambda 1$. Together with the allergen induced cytokines IL-25, IL-33 and TSLP, ILC2s are activated and produce more type 2 cytokines. Subepithelial plasmacytoid dendritic cells (pDCs) recognize virus antigens and present them to $\mathrm{CD} 4^{+} \mathrm{T}$ cells and $\mathrm{CD}^{+}{ }^{+} \mathrm{T}$ cells through MHC class II or I, and drive them towards a more type 2 centric response. Excessive release of chemokines and cytokines can be triggered by infections such as respiratory-syncytial virus (RSV). Together with type 2 cytokines, they could further promote the function of type 2 macrophages, a small fraction of IL-4-secreting NK cells, IL-4-secreting NK-T cells, neutrophils, eosinophils and mast cells, and augment type 2 responses in chronically inflamed airways. With the production of perforin and granzymes, $\mathrm{CD}^{+} \mathrm{T}$ cells can show cytotoxicity to virus-infected epithelial cells and induce apoptosis. The viral RNA is released and detected by airway smooth muscle cells and stimulates the production of prostaglandins (PGs) in an autocrine manner.

Figure 5: Biomarkers in food allergy diagnosis and treatment outcomes prediction. Conventional clinical approaches to diagnose food allergy include family history, skin integrity and the oral food challenge. Nowadays, expanded approaches focusing on genetic risk factors, allergen-specific and non-specific humoral and cellular biomarkers were explored. Genome, epigenome and mRNA linked to epithelial integrity and barrier (dys)function are linked to the development of food allergy. The measurement of IgE and IgG4 binding to linear or conformational epitopes could be more powerful to diagnose food allergy than conventional approaches. The soluble high-affinity $\mathrm{IgE}$ receptor (FceRI) may also act as a biomarker for IgE mediated pathologies in a less allergen independent way. Moreover, allergen-specific Th2A cells and memory B cells have been discovered as new cellular biomarkers. Functional tests that simulate allergen exposure in vitro or ex vivo like the basophil activation test (BAT) and mast cell activation test (MAT) offer the possibility to assess allergen induced IgE crosslinking.

Figure 6: Mechanisms of immune-mediated reactions to drugs. These reactions encompass immediate reactions (mediated by IgE), and non-immediate reactions (mediated by $\mathrm{T}$ cells). In immediate reactions, drug-induced polarization of Th2 cells from Th0 cells, promote B cells to produce specific IgE (sIgE). These sIgE bind to the FceRI receptor on mast cells. In subsequent drug contacts, the simultaneous recognition by at least two sIgE initiates the degranulation and release of mediators. Non-immediate reactions are generally characterized by a Th1 response with the increased secretion of IFN $-\gamma$ from Th1 cells and granulysin from NK cells.

Figure 7: Mechanisms of cross-reactive hypersensitivity reactions to NSAIDs. NSAIDs induce reactions relying on their COX-1 inhibitory activity, i.e. activation of mast cells and other immune cells without involvement of adaptive immunity. During NSAID-exacerbated respiratory disease (NERD), the administration of NSAIDs permits strong 5-lipoxygenase (5LOX) activation and further generation of leukotriene E4 (LTE4). LTE4 induce the release of IL-33 and TSLP, and consequent mast-cell activation, with bronchoconstriction occurring as a result of the direct effects of leukotriene C4 (LTC4), prostaglandin D2 (PGD2), and other mast cell-derived products. PGD2 recruits effector cells such as Th2 cells, group 2 innate cells (ILC2s), basophils and eosinophils to the airway. Consistently, in NSAIDs-exacerbated cutaneous disease (NECD) and NSAIDs-induced urticarial-angioedema (NIUA), increased PGD2 can act on the skin epidermis. In addition, cross-reactive hypersensitivity to NSAIDs may involve additional sources of inflam- 
matory mediators, such as eosinophils and platelets. ILC2: innate lymphoid cells 2; LTE4/C4: leukotriene E4/C4; NSAID: Non-steroidal anti-inflammatory drugs; PGD2: prostaglandin D2; TSLP: thymic stromal lymphopoietin; 5LOX: 5-lipooxygenase.

Figure 8: Current view on mechanism and biomarkers in use to monitor AIT. A. Scheme of immune modulation by AIT, where low dose, repeated exposure to allergen is thought to occur with limited to no inflammation. As a result, Th skewing is balanced towards Th1 and Treg, which subsequently modify the B-cell response. Especially the production of IL-10 is thought to drive IgG4 class switching. Thus, local and systemic memory is rebalanced, both in the T-cell and the B-cell compartment, and there is a strong increase in allergen-specific IgG4 antibodies. Upon allergen challenge, IgG4 and potentially other soluble factors are thought to inhibit IgE-mediated degranulation of target cells, i.e. desensitization. Together with the loss of Th2 skewing, this underlies the observed clinical tolerance. B. Laboratory biomarkers utilized in diagnostics and clinical trials for AIT (adapted from ${ }^{230}$ ). Abbreviations: IgE-FAB, IgE-facilitated allergen binding; IgE-BF, IgE-blocking factor; BHR, basophil histamine release; DAO, diamine oxidase; Treg, regulatory $\mathrm{T}$ cell; Breg, regulatory B-cell; DC, dendritic cell. Figure reproduced from ${ }^{228}$.

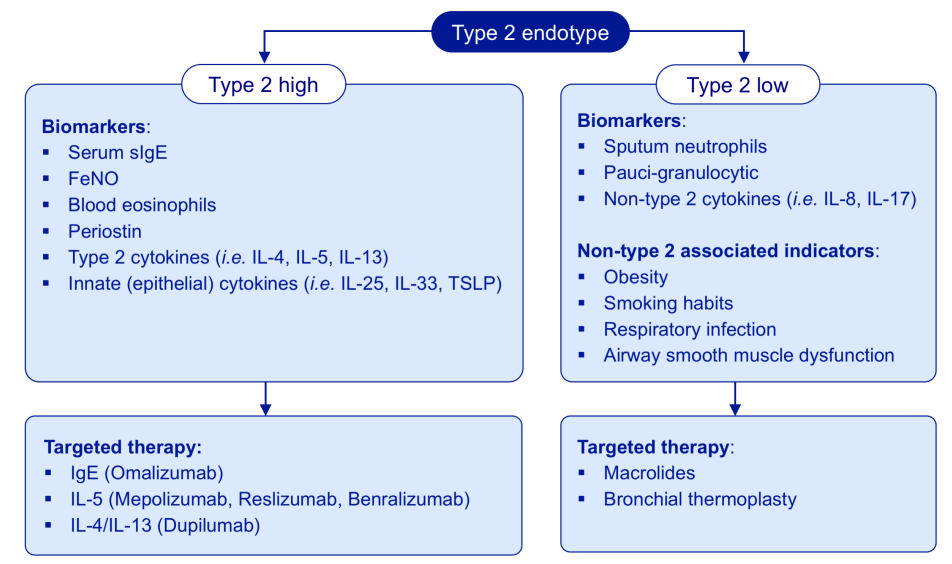

High risk of childhood asthma

\begin{tabular}{|l|l|}
\hline Increase in relative abundance: \\
\hline Veillonella \\
Prevotella \\
Gemella \\
Deraxella
\end{tabular}




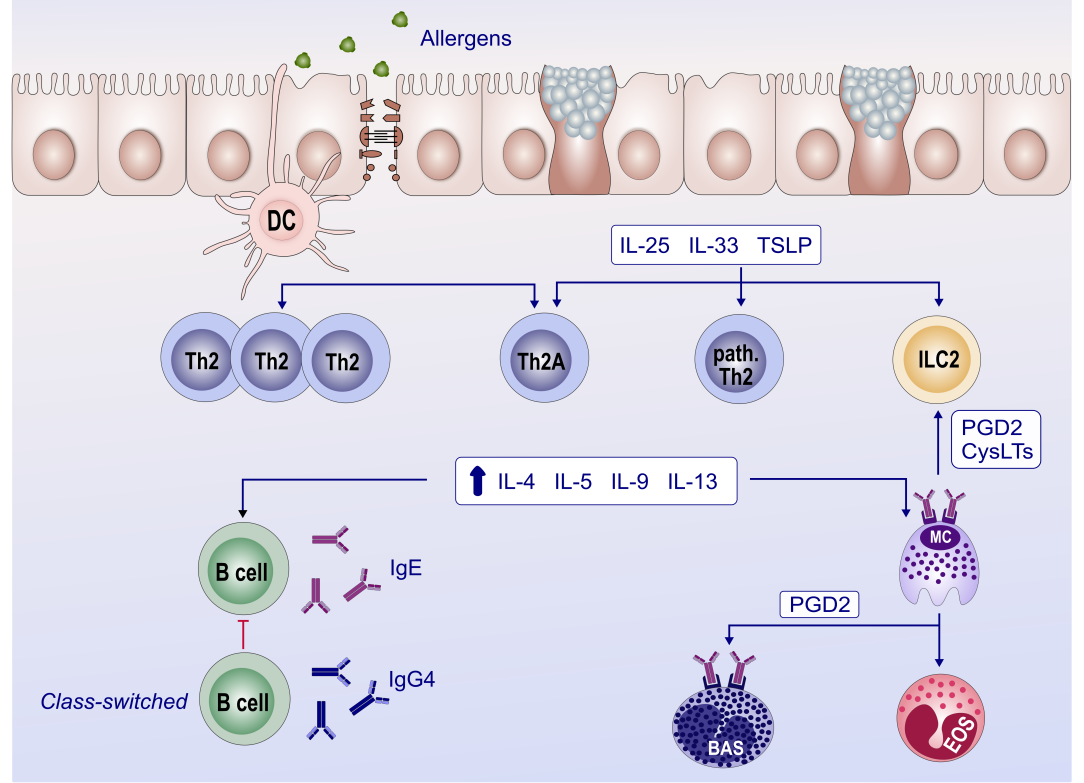

Biomarkers of viral infections in exacerbations of AR

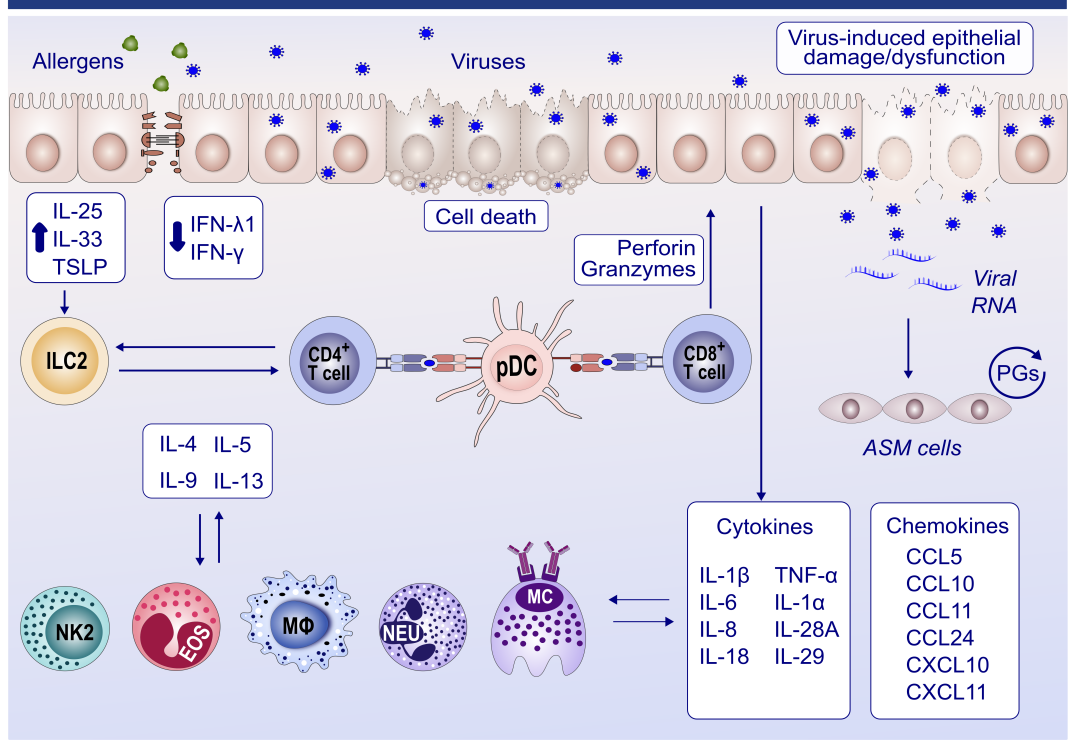




\begin{tabular}{|ccc|}
\hline Clinical Markers & Provocation Testing & Genetic Markers \\
$\begin{array}{c}\text { Family History } \\
\text { Eczema/Skin Integrity } \\
\text { Severity }\end{array}$ & $\begin{array}{c}\text { Food challenge } \\
\text { Skin testing }\end{array}$ & $\begin{array}{c}\text { Genome } \\
\text { Epigenome } \\
\text { mRNA }\end{array}$ \\
\hline
\end{tabular}

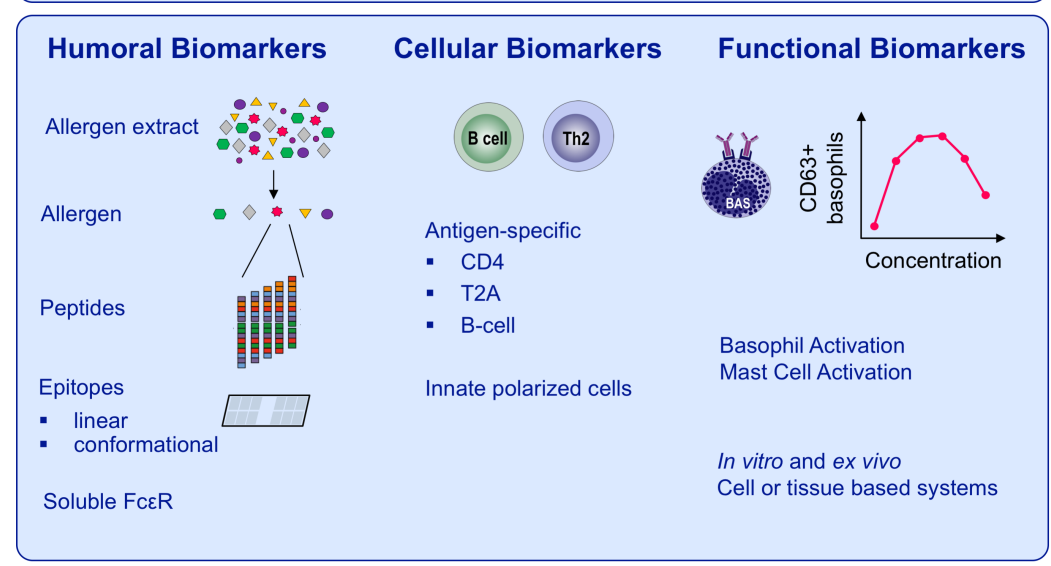
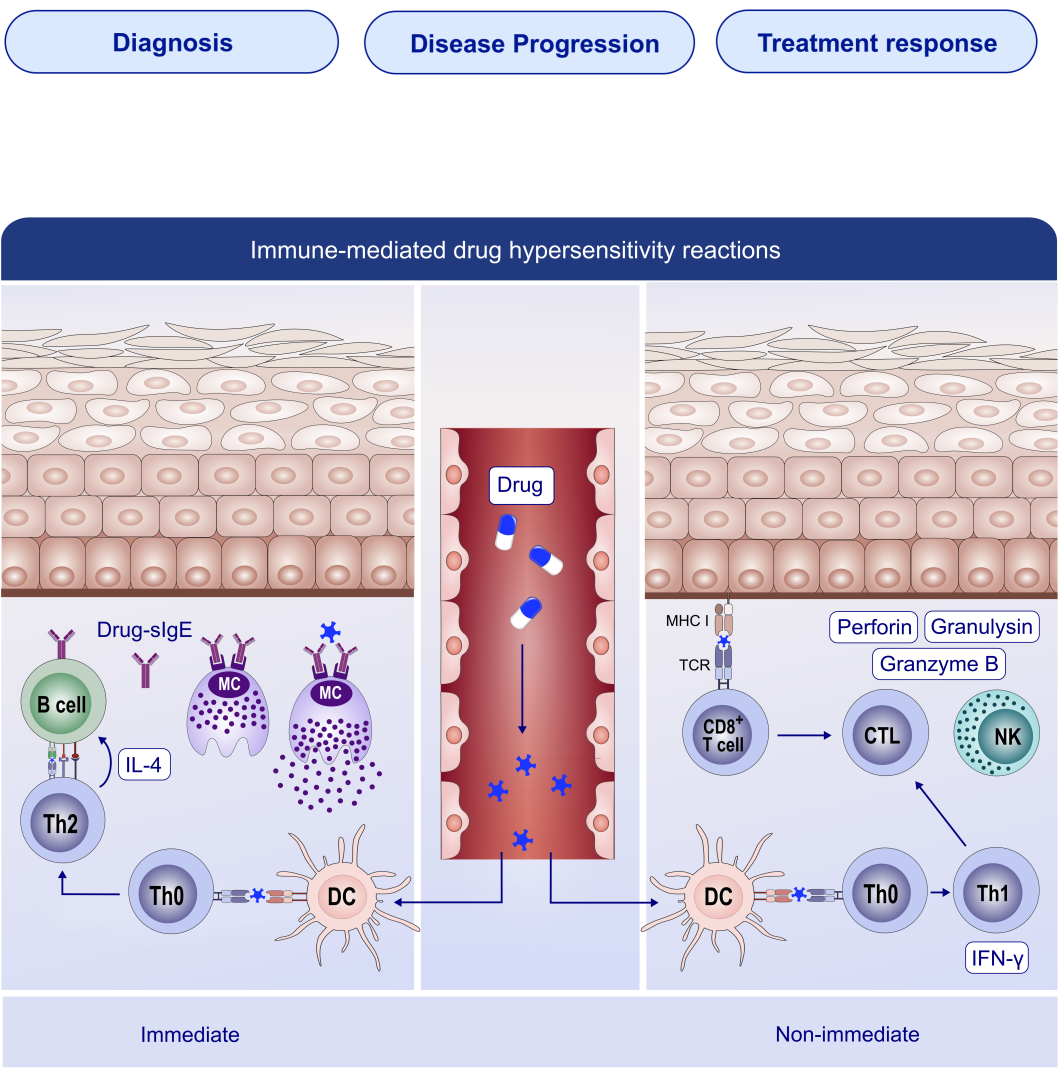
Cross-reactive NSAIDs hypersensitivity

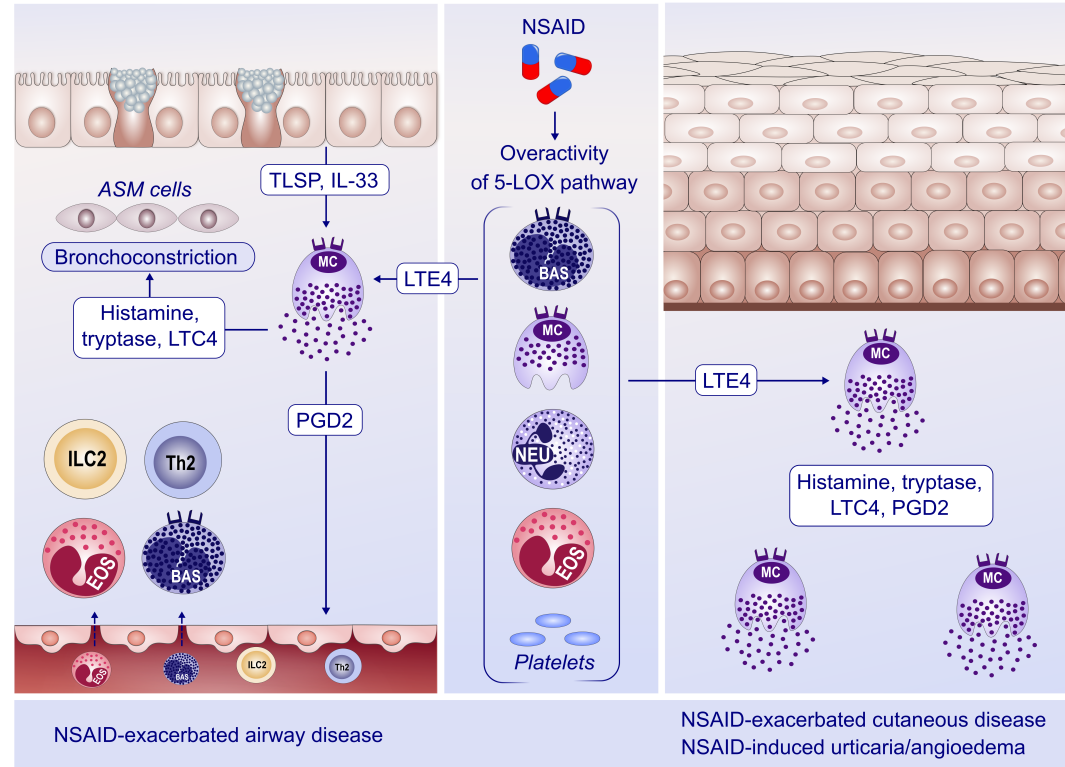


(A)

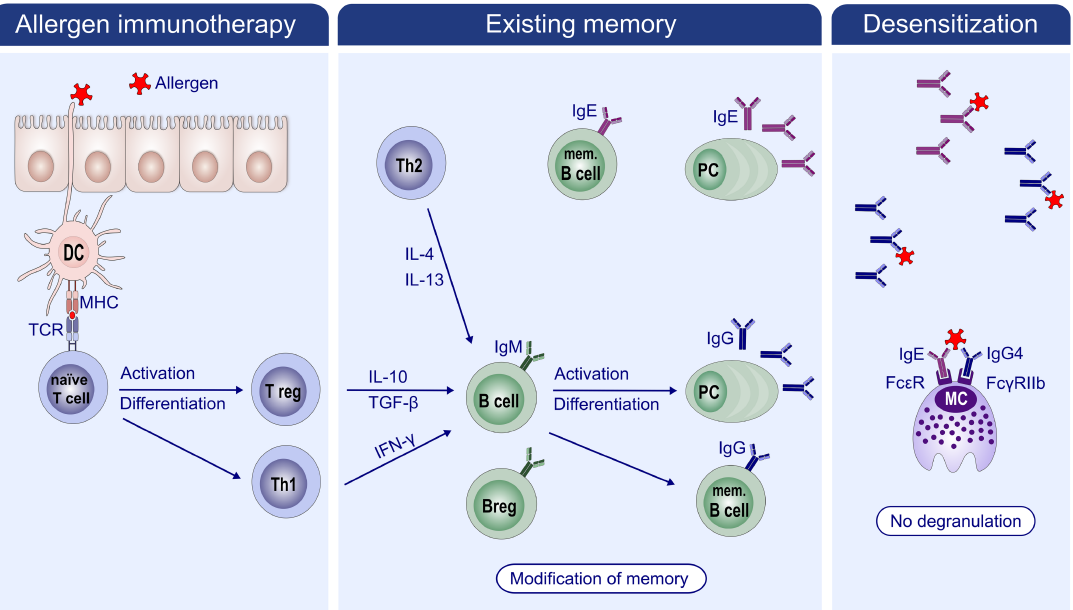

(B)

\begin{tabular}{|c|c|c|c|c|}
\hline Domain & Type of target & Assays & Strengths & Limitations \\
\hline I: IgE & Serum protein & $\begin{array}{l}\text { Total IgE } \\
\text { Allergen-specific lgE }\end{array}$ & $\begin{array}{l}\text { Serum markers; } \\
\text { slgE gold standard } \\
\text { patient selection for AIT }\end{array}$ & $\begin{array}{l}\text { No correlation of levels with therapy } \\
\text { success }\end{array}$ \\
\hline $\begin{array}{l}\text { II: } \\
\text { IgG subclasses }\end{array}$ & Serum protein & $\begin{array}{l}\text { Allergen-specific lgG1 } \\
\text { Allergen-specific IgG4 }\end{array}$ & $\begin{array}{l}\text { Serum markers; slgG } 4 \\
\text { elevated by AIT }\end{array}$ & $\begin{array}{l}\text { Failure in slgG4 induction might } \\
\text { reflect inadequate treatment } \\
\text { compliance }\end{array}$ \\
\hline $\begin{array}{l}\text { III: } \\
\text { Serum inhibitory } \\
\text { activity for IgE }\end{array}$ & Serum protein & $\begin{array}{l}\text { IgE-FAB } \\
\text { IgE-BF }\end{array}$ & $\begin{array}{l}\text { Serum-based assay; } \\
\text { functional output }\end{array}$ & $\begin{array}{l}\text { Laborious and requires specialized } \\
\text { reagents/equipment }\end{array}$ \\
\hline $\begin{array}{l}\text { IV: Basophil } \\
\text { activation }\end{array}$ & Cell activation & $\begin{array}{l}\text { Flow cytometry of allergen- } \\
\text { activated basophils (CD63, } \\
\text { CD203c, BHR, DAO) }\end{array}$ & $\begin{array}{l}\text { Requires small amount } \\
\text { of blood }\end{array}$ & $\begin{array}{l}\text { In vitro assay, which is difficult } \\
\text { to optimize and standardize }\end{array}$ \\
\hline $\begin{array}{l}\mathrm{V} \text { : Cytokines } \\
\text { and chemokines }\end{array}$ & Serum protein & $\begin{array}{l}\text { ELISA or Luminex for: } \\
\text { IL-2, IL-2R, IL-4/5/6, IL-8/9/10, } \\
\text { IL-13/18, IFN- } Y \text {, ECP, Eotaxin, } \\
\text { MCP-1, TARC, transthyretin }\end{array}$ & $\begin{array}{l}\text { Serum-based assay; } \\
\text { high-throughput }\end{array}$ & $\begin{array}{l}\text { Low sensitivity for many cytokines } \\
\text { in serum }\end{array}$ \\
\hline $\begin{array}{l}\text { VI: Cellular } \\
\text { biomarkers }\end{array}$ & $\begin{array}{l}\text { Cell phenotyping / } \\
\text { activation }\end{array}$ & $\begin{array}{l}\text { Immunophenotyping of ex vivo } \\
\text { or in vitro activated cells: } \\
\text { CD4+ T cells, Treg, Breg, DC }\end{array}$ & $\begin{array}{l}\text { Multiple cell subsets } \\
\text { can be measured in } \\
\text { single analysis from } \\
\text { small blood sample }\end{array}$ & $\begin{array}{l}\text { Lack of standardization in definitions } \\
\text { and evaluation of most cell types. } \\
\text { Antigen-specific cells can currently } \\
\text { only be measured after in vitro } \\
\text { culture (laborious) }\end{array}$ \\
\hline
\end{tabular}

